\title{
¿Patriotas, educadores, empresarios o burócratas? El papel de los primeros empleados públicos en la conformación del Estado costarricense, 1821-1858 \\ Patriots, Educators, Entrepreneurs, or Bureaucrats? The Role Played by the First Civil Servants in the Creation of the Costa Rican State, 1821-1858
}

Pablo Augusto Rodríguez Solano Universidad de Costa Rica pablo.rodriguez_s@ucr.ac.cr ORCID: orcid.org/0000-0001-7489-0067

Resumen:

En este artículo se discute la forma en que se ha comprendido la conformación del entramado institucional costarricense, a partir de la revisión del modelo weberiano de burocracia, analizando las características específicas del empleo público en esas primeras oficinas estatales, para determinar si es adecuado el uso del término "burócrata" para estos primeros funcionarios. Este documento se basa en los resultados iniciales de un proyecto de investigación titulado "Conformación de un discurso oficial sobre la burocracia y su papel en la consolidación del Estado, a través del estudio de leyes y periódicos entre 1839 y 1890", presentado ante el Centro de Investigación en Identidad y Cultura Latinoamericanas (CIICLA) de la Universidad de Costa Rica. Se pretende enlazar la conformación de los cuerpos burocrático-administrativos de los nacientes Estados latinoamericanos, con la consolidación de sus estructuras políticas y su discurso de nación.

Palabras clave: burocracia, funcionarios, instituciones, Costa Rica, Centroamérica.

\section{Abstract:}

This article discusses the way in which the creation of the Costa Rican institutional warp and weft has been understood based on a revision of the Weberian model of bureaucracy. It analyzes the specific characteristics of public employment in the first State offices, in order to decide whether or not it is appropriate to use the term "bureaucrat" in describing these first public officials. This document is based on the first research results of a project entitled "Creation of an Official Discourse on Bureaucracy and its Role in the Consolidation of the State through a Study of the Laws and Periodicals between 1839 and 1890," presented at CIICLA (the Research Center on Latin American Identity and Culture), pertaining to the University of Costa Rica. This project aims to link the creation of the bureaucratic-administrative bodies of the emerging States in Latin America to the consolidation of their political structures and their discourse as nations.

Keywords: bureaucracy, civil servants, institutions, Costa Rica, Central America. 


\section{Introducción}

a investigación a partir de la cual se deriva este artículo parte de las siguientes preguntas: ¿A partir de qué punto las administraciones de los nuevos estados en Centroamérica comenzaron a producir una burocracia estatal? ¿Cómo podemos relacionar esa primera burocracia con la conformación de los entramados institucionales que ayudaron a consolidar los Estados y sus posteriores discursos de nación? Con base en tales interrogantes se revisan las características de los primeros empleados públicos en la administración costarricense, con el fin de plantear una discusión más amplia sobre las transformaciones que ocurrieron en los cuerpos políticos del país en esas primeras décadas. Se pretende establecer un primer marco de análisis sobre la naturaleza de los cuerpos burocráticos en la región, así como su importancia en la consolidación de sus instituciones estatales.

Para realizar este análisis se parte de tres perspectivas complementarias. La primera revisa el modelo desde el cual se ha estudiado la burocracia en la región, en contraste con las bases sobre las que se conformó el ideal de burócrata en Costa Rica. Con fundamento en la teoría de Max Weber se busca plantear, en el contexto de los Estados centroamericanos, una posible nueva interpretación sobre la naturaleza de la organización burocrática en la zona. La segunda perspectiva comprende la conformación del entramado institucional administrativo, su despliegue y sus características, lo cual nos permitirá contextualizar el desarrollo del empleo público en Costa Rica. La tercera es la transformación del marco legal en el cual se legitima el accionar burocrático en el Estado, para así definir plenamente el papel de los primeros empleados públicos del gobierno costarricense.

Para ello se parte de una revisión exhaustiva y crítica de las leyes del Estado costarricense, las cuales nos darán un panorama general sobre las transformaciones del objeto de estudio propuesto. Es evidente que para realizar este análisis debe tenerse cuidado con la relación entre la letra de la ley y la realidad de su aplicación. No obstante, es una excelente plataforma para discutir la conformación de la burocracia, precisamente porque permite apreciar las estructuras estatales de los nuevos cuerpos políticos, así como la transformación de estas, desde el marco de un derecho primariamente subjetivo, basado en la costumbre, a uno principalmente objetivo, representado en la letra de la ley.

Costa Rica, igual que las demás provincias del Reino de Guatemala, atravesaron un proceso conflictivo a lo largo del siglo XIX, que tuvo como resultado 
la consolidación más o menos estable de un cuerpo político estatal. No obstante, su independencia no dependió de grandes batallas frente a los ejércitos de la corona española, ni se vio protagonizada por potentes movimientos sociales como los que se vieron en México o en Sudamérica. Fue un proceso mucho más planificado, orientado al mantenimiento de un orden ya establecido (Rodríguez, 2013a). En ese sentido, la formación de instituciones y un funcionariado en cada provincia no estuvo relacionado con la caótica reestructuración posrevolucionaria, sino con la adaptación y transformación de un entramado colonial, que se mantuvo prácticamente intacto. El objetivo era la conservación y su reforzamiento, no una transformación radical (Sarazúa, 2013; Rodríguez, 2013b).

Esto, a su vez, significó el mantenimiento de un orden legal basado tanto en la normativa real como en la costumbre y las formas de un pactismo con profundas raíces en el derecho y la filosofía hispana. Estas bases fueron progresivamente alteradas a partir de nuevas ideologías, pero principalmente del inevitable proceso de prueba y error que siguió a la independencia. A partir de lo anterior se plantea la necesidad de revisar con cuidado las bases sobre las cuales se comprende la constitución de la burocracia estatal en nuestros Estados, lo que nos obliga a una revisión de la forma en que hemos utilizado la teoría sobre su formación, aplicada al contexto Centroamericano. Este artículo no pretende ser definitivo, sino abrir una discusión más amplia sobre este tema, que resulta de capital importancia para la comprensión de la historia regional.

\section{Weber en Centroamérica: discusión sobre las bases de la burocracia}

los funcionarios i empleados subalternos, encargados de la administración de justicia no permitan que en lo sucesivo queden delitos impunes, bajo pretexto de no estar probados, i que severos en sus funciones, honrados i fieles al pueblo que los elevó al Poder no oigan la voz de la seducción, ni vuelvan los ojos al oro que se desmenuza en las manos del Juez que vende su conciencia: esperemos que las autoridades políticas administrarán mejor los fondos de los pueblos, compondrán caminos particulares, procurarán edificar cárceles seguras i bien ordenadas i mejorarán las escuelas de los barrios que han permanecido estacionarias por muchos años ("Las Esperanzas", en El Costarricense, semanario oficial, 9 de enero de 1847: 30). 
El análisis en este apartado no pretende ser una revisión extensiva o una crítica de la teoría de Weber, sino un aporte analítico sobre el uso del término burocracia en Costa Rica, en el contexto de la definición del Estado. Hay que comenzar reconociendo que la idea de una burocracia en los momentos iniciales de formación del Estado, aunque tentadora, parece muy improbable. Precisamente, Weber previene a cualquiera que desee hacerlo, al señalar que "una autoridad burocrática perdurable y pública, jurisdiccionalmente determinada, constituye normalmente una excepción y no una regla histórica" (Weber, 2011: 4). La burocracia no es un fenómeno que surja de manera automática ante la constitución de una institucionalidad administrativa, lo que sucede es que existe una tendencia a equiparar administración y burocracia.

Planteada tal cual, la idea de una burocracia, según Weber, parece estar limitada al contexto específico de un Estado moderno. Esto no resulta extraño si se considera que el concepto nació a partir del análisis que el autor realizó del Estado prusiano de su época, lo que implica condiciones sociales, económicas y culturales específicas. Una lectura más cuidadosa de las ideas de Weber permite comprender que la burocracia no es un fenómeno transhistórico, presente en todas las épocas y contextos culturales. Aspecto que está muy en consonancia con la forma en que el mismo Weber considera o define los problemas de la racionalidad como un fenómeno histórico (Munné, 2006: 70-71). Por lo tanto, la burocracia es tanto un fenómeno cultural como histórico, por lo cual no es posible explicarla como resultado automático de la existencia de una administración o de un poder central. Según Huaylupo (2009), esto implica comprenderla como un medio por el cual los Estados logran articularse con sus sociedades. Aspecto que demanda la comprensión más específica de las relaciones políticas y el devenir de los Estados en el tiempo, para considerar las condiciones particulares en las que cada uno desarrolló su propia forma de burocracia.

Adicionalmente, esto obliga a considerar la diferencia presente entre los términos de funcionario o empleado y el de burócrata. Según Weber, la burocracia es la máxima expresión de la conformación de un tipo de dominación basada en una lógica legal-racional, que permite la predictibilidad de las normas sociales y políticas en el desarrollo de una economía de mercado (Weber, 1987: 20). Para este autor, la creación de los Estados-nación posibilitó las condiciones que facilitaron la subsistencia del capitalismo como sistema. En ese sentido, gran parte de la teoría del Estado sostenida por Weber se basa en la existencia de estructuras jurídicas, que apuntalan la consolidación de un sistema de capital sin el cual re- 
sulta imposible establecer la burocracia necesaria para mantener el sistema en su conjunto. En ese sentido, "la moderna empresa capitalista racional necesita tanto de la calculabilidad de los medios técnicos del trabajo como de un derecho previsible y una administración guiada por reglas formales" (Munné, 2006: 85).

En Costa Rica, aunque no de manera explícita, esto ha permitido una explicación de la constitución del Estado como un fenómeno ligado a la consolidación del liberalismo en la década de 1870-1880, como precursor de una "cultura cívica moderna" (Molina y Palmer, 2012). Lo que se ha manifestado en la comprensión de la burocracia como una circunstancia de la transformación de los sistemas económicos y políticos de los últimos 25 años del siglo XIX, que a su vez se encadenan con las circunstancias económicas desarrolladas en la primera mitad del siglo —especialmente con el surgimiento del café-. A partir de lo anterior, esta posición reconoce que la constitución definitiva de la lógica legal racional, que sustenta tanto al Estado como a la nación, son posibles solo después de las transformaciones políticas de la década de 1870, cuando además se expande y consolida definitivamente un sistema de mercado de capitales a partir del café, que ya venía desarrollándose desde la década de 1840.

Para Weber un requisito fundamental para la formación de una administración burocrática era la existencia de una economía monetaria estable y bien conformada, que permitiera el surgimiento de una clase social que pudiera vivir de su trabajo, alejada de los sectores de producción primarios y secundarios de la economía. En resumen, algunas de las características centrales del trabajo burocrático estaban dominadas por esta lógica racional; entre las principales se pueden mencionar:

- Conducta ligada a la norma legal. Rutinas, procedimientos y comportamientos estandarizados en guías, manuales y leyes.

- Una clara y específica división de las esferas de competencia (jurisdicción), lo cual establece también una división especializada de las labores en la oficina.

- Cadena jerárquica establecida.

- Desarrollo de conocimiento técnico especializado que requiere entrenamiento y facilita la existencia de un sistema meritocrático.

- El personal debe estar separado de la propiedad de los medios de producción (distintos medios de capital) y administración (que la creación y administración de leyes está fuera de los medios del burócrata como tal).

- Completa previsibilidad del funcionamiento de las oficinas y la administración. 
A partir de esta caracterización podemos establecer algunos paralelismos con el análisis sobre la burocracia en Costa Rica. Se puede argumentar que, en algún momento de la década de 1840, o principios de la década de 1850, la administración cumple, al menos formalmente, con casi todas las características señaladas. No obstante, como podrá apreciarse en el resto del artículo, la capacidad del gobierno de hacerse obedecer encontró resistencia constante por parte de funcionarios locales, soldados y otros, lo cual nos recuerda la diferencia entre la normativa y la práctica de la ley. A pesar de ello, es precisamente esta resistencia lo que nos permite descubrir algunas de las características claves que diferencian a la administración pública del modelo weberiano y, por ende, nos explican la necesidad de una nueva perspectiva de análisis. Hay dos aspectos del ideal burocrático de Weber que no se cumplen a cabalidad sino hasta varias décadas después: la separación de los medios de producción y administración, así como el desarrollo de un conocimiento técnico especializado sobre el funcionamiento de la oficina. Ambas condiciones podrían indicar la falta de una burocracia en los términos definidos por el mismo Weber.

No obstante, en este artículo se afirma que a finales de la década de 1840 ya es posible hablar de una burocracia estatal en Costa Rica. Es necesario replantear nuestra comprensión sobre la consolidación del Estado en Centroamérica, para incluir la posibilidad de una lógica legal diferente al liberalismo, la cual podría darnos una respuesta más convincente sobre las formas en que el Estado resolvió la relación entre el gobierno y la sociedad o, dicho por Huaylupo (2009), cómo los Estados logran articularse con sus sociedades. Hay, detrás de las acciones del gobierno de Costa Rica, dos comportamientos recurrentes que no parecen ajustarse a la lógica de un sistema liberal.

En la legislación del Estado hay un importante esfuerzo por definir claramente la condición de los burócratas como "representantes del Estado", lo que pretendía impedir a los empleados públicos robar de las cajas de la Hacienda. Sin embargo, esto no significó una limitación para la participación de estos como sujetos privados en la economía, haciendo que este comportamiento no solo fuera tolerado, sino incluso incentivado, aspecto que se observa también en los demás Estados centroamericanos. Es una contradicción con el modelo weberiano que apuntamos páginas atrás, el cual demanda la completa separación de los burócratas de la economía privada.

No obstante, la contradicción solo resulta aparente, ya que se relaciona con la forma en que el Estado se consolidó en la región. En el caso de Costa Rica, 
las condiciones del proyecto político habían facilitado la construcción de un modelo centralizado, que comenzó a consolidarse rápidamente a partir de la década de 1840, gracias a la introducción de las ganancias del café (Williams, 1994: 156-163). Pero esto no significa que estas instituciones funcionaran únicamente a partir de una lógica republicana liberal — hacer esa suposición implicaría defender que la independencia marcó una línea definitiva, donde "lo colonial" acabó por dar paso a una lógica liberal de la noche a la mañana-. Una forma de apreciar lo intricado del proceso que se menciona en estas cuartillas es mediante una revisión de las cajas de Hacienda.

Desde 1821 las cajas del Estado fueron deficitarias, lo que obligó a una discusión sobre la mejor forma de recaudar y lo costoso de una administración pública (Rodríguez, 2014: 260-261). Este debate resulta de interés precisamente porque demuestra lo débil y problemática que resultaba la administración del Estado, al menos durante las primeras dos o tres décadas de su existencia. En 1838, una comisión especial sobre Hacienda señalaba:

Los ramos que al presente tiene el Estado producirían lo bastante para llenar sus gastos precisos si todos y cada uno fueran rematados en subasta pública en favor de particulares que como interesados harían la esación (sic) justa de lo que les correspondía, y de este medio sin recargar al público con nuevos impuestos la Hacienda podría contar con una cantidad fija de que disponer sin sujetarse de fraudes, gastos y abusos a que está expuesta en la presente administración de ellos. En los pueblos reducidos y distantes se hace impracticable la recaudación de los productos de dichos ramos porque siendo en ellos muy pocos los individuos que poseen las cualidades de aptitud y honradez, cuando se les encarga la administración, se excusan por varios motivos, de suerte que por fuerza viene a caer en manos de abandonados e ineptos; y si como de esta clase se dificulta encontrar quien desempeñe las Receptorías, deben recaer por disposición gubernativa en los Alcaldes $2^{\circ}$ que regularmente no saben firmar, y a quienes no se los puede exigir cuenta así responsabilidad alguna por razón de la insuficiencia de los destinos de que resulta que sin aliviar al Pueblo de las contribuciones decretadas, la Hacienda del Estado no reporta ninguna ventaja (ANCR, Hacienda, 4.666, ff. 7-7v).

Pero entonces ¿por qué no se arrendaron las oficinas de recaudación a lo largo de todo el periodo?, más aún, ¿cómo se explica el aumento sostenido de los ingresos del Estado? (gráfica 1). Dos elementos a considerar son, por un lado, el aumento de las rentas producidas por el café, que arrastró los procesos de producción y con ello la recaudación; por otro, la mejor definición de funciones, 
jurisdicciones y la ampliación de capacidades de cobro en la hacienda estatal. Pero además deberíamos señalar una condición que tal vez pueda pasar inadvertida, oculta por el mismo discurso oficial: esos funcionarios "ineptos", por su falta de conocimiento formal, eran efectivos en el manejo de las relaciones informales en el campo. Eran personas que tenían una "voz" entre los pueblos y capaces de comandar autoridad en el plano local. Por lo que, en realidad, es de suponer que el gobierno se aprovechaba de una relación muy especial, facilitada por un proceso de captación de estos individuos en el marco de actuación legal del Estado, lo que, sin duda, también se asemeja al caso guatemalteco.

Gráfica 1. Porcentajes de ingresos de la Hacienda de Costa Rica por quinquenios, del total en el periodo 1825-1859.

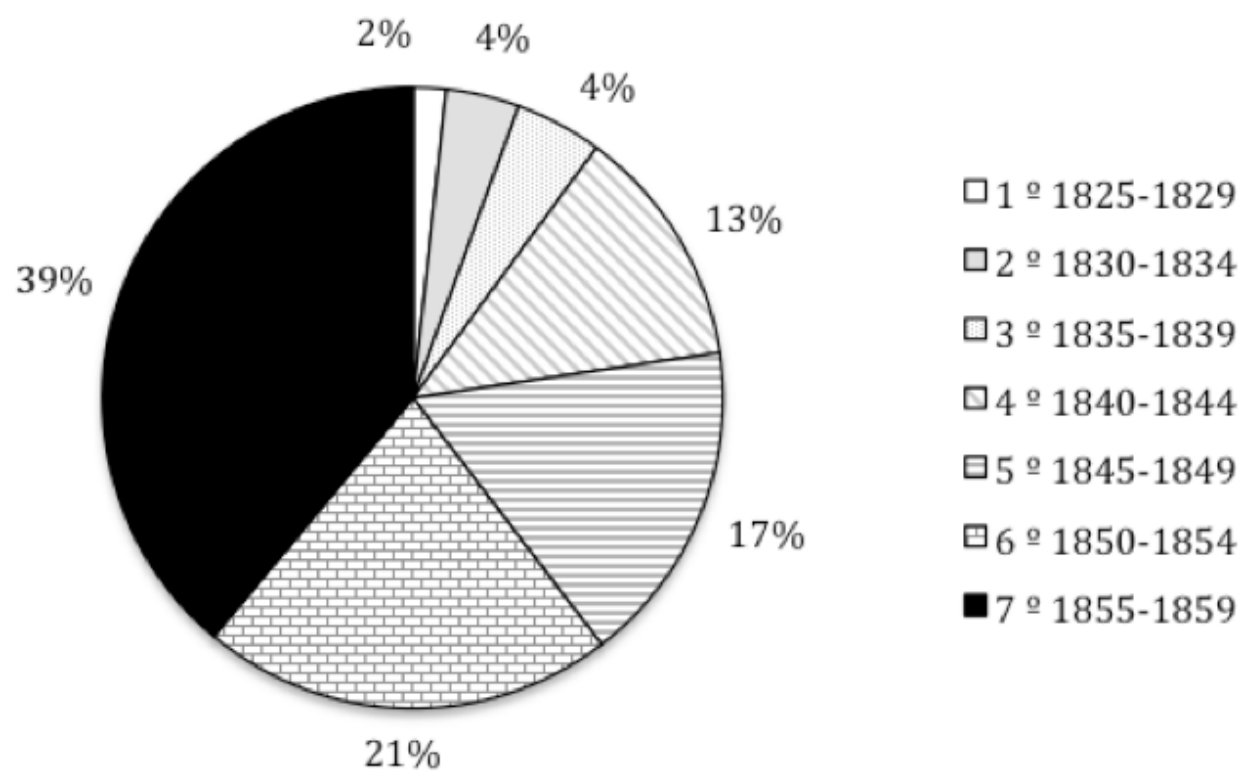

Nota. Los datos del quinquenio 1820-1824 resultan muy poco fiables, por eso se excluyen. Fuente: Rodríguez, 2014: 350.

Las primeras reformas burocráticas aplicadas en Costa Rica se llevaron a cabo en las oficinas de Hacienda, cuyo problema fundamental era financiar el gobierno. Esto, aunque resulta obvio ante los espectadores contemporáneos, no era de sencilla solución para los primeros administradores de la época. El problema fundamental era reunir la experiencia técnica necesaria, vencer la resistencia de individuos y otras instituciones y colectivos con poder en el territorio, así como 
normalizar el comportamiento de las relaciones socio-económicas internas del Estado. A partir lo anterior, se sugiere que la solución fue permitir que las relaciones informales, sancionadas por la costumbre en el quehacer diario del mundo socio-económico costarricense, permearan la forma de hacer política y manejar la labor administrativa en las oficinas. Una lógica corporativa, que impregnó cada uno de los aspectos centrales de cómo "formar gobierno", a la manera de ver Juan Mora Fernández, primer Jefe de Estado de Costa Rica.

En ese sentido, el complejo pago de los salarios a los empleados públicos nos dice mucho de esta relación. En 1844 se ordenó que los empleados públicos no podían pedir adelantos de sueldos, y que debían esperarse a recibirlo de manera mensual. No obstante, en junio de ese año se llegó a la conclusión de que no se había reunido suficiente capital para pagar los salarios, por lo que se destinaron 16000 pesos, provenientes de un contrato de tabaco, para abastecer las tercenas de Nicaragua, para pagar a los funcionarios ("Orden XI", en Colección de leyes y decretos 1844: 300-301). Ese mismo año se aprobó otro decreto, en el cual se señalaba que, aunque dicha orden había sido ejecutada, solo había servido para pagar la mitad de la deuda anual, por lo que "siendo de justicia preparar nuevos recursos para la amortización de la deuda indicada hasta el fin del próximo diciembre" sería necesario recurrir de nuevo al dinero producido por la venta de tabaco a Nicaragua ("Resolución XVIII", en Colección de leyes y decretos 1844: 395-396).

Ante estas condiciones, el recurso al pago de sueldos por medio de la creación de pagarés o vales se hizo común. Estos papeles luego se podían cambiar en las aduanas, en la compra de tierras o en otros negocios, lo que hizo de la deuda interna un elemento estructural de la economía del Estado, transformándola en una moneda de intercambio (Rodríguez, 2014: 331). Pero esto solo da cuenta de una parte de los mecanismos por los cuales los burócratas eran retribuidos. En algunas oficinas, como las receptorías, encargadas de la recolección de la alcabala de tierra, los funcionarios llegaban a consumir una proporción de lo recaudado, antes de que llegara a las cajas de Hacienda. En 1835, por ejemplo, de 4260 pesos recaudados, solo llegaron a la caja del Estado 1562 pesos (ANCR, Hacienda, 11 304, 11 306, 11 309, 11 311, 11 356, 11 386, 11 543, 12 989, 13 121, 13 122, 14 042, 14 838, 17 624).

A pesar de las constantes restricciones, para que los empleados del Estado no incurrieran en negocios de comercio, las leyes y regulaciones del mismo gobierno toleraban e incluso alentaban estas conductas. Al mismo tiempo se desarro- 
Ilaban cuatro formas complementarias de pago de sueldo. La primera incluía el salario que cada burócrata tenía establecido. La segunda permitía a los funcionarios interactuar en el mercado de deuda, potenciado por la incapacidad de pagar los sueldos del gobierno, y en el cual se podían recibir adelantos en efectivo al vender los pagarés o vales, obtener beneficios en el pago de alcabalas, o comprar tierras directamente. La tercera era una forma de pago por explotación de recaudación, en la cual los empleados eran capaces de satisfacer sus sueldos de la recaudación de las cajas que ellos mismos administraban. Por último, participar directamente de negocios de comercio privado, para lo cual se contó con permiso a lo largo de la década de 1840, aunque progresivamente fue restringido.

Weber advierte que la falta de una economía monetizada, así como la imposibilidad de la autoridad de garantizar una administración férreamente centralizada puede producir la necesidad de permitir a los funcionarios vivir de excedentes, o incluso de porcentajes de cobro (Weber, 2011: 25). Y afirma que:

La índole del sistema de explotación de la recaudación está esencialmente determinada por la influencia conjunta o antagónica de estos motivos: la eliminación de fluctuaciones en la recaudación, la posibilidad de un presupuesto, la preservación de la capacidad de pago de los súbditos, protegiéndolos de la explotación económica, y un control estatal de las recaudaciones del funcionario a fin de adjudicarse el máximo posible (Weber, 2011: 27).

Pero, aunque un sistema de explotación de recaudación puede ser percibido como un obstáculo para la formación de una burocracia, se puede afirmar que la particular combinación de estos factores, con las características del pacto político costarricense, fue lo que facilitó la consolidación de las oficinas burocráticas. En ese sentido, los datos parecen apuntar que no fue la conformación de una economía monetizada capitalista lo que empujó al desarrollo de las estructuras administrativas del Estado en primera instancia, aunque su papel en la consolidación de estas a partir de 1840 sea innegable. Parece ser que el principal motor de este proceso es el control de los medios y las capacidades para delimitar la sociedad civil y consolidar el poder central del gobierno, y a partir de estas, del discurso sobre el poder, así como del papel y la relación del Estado en la sociedad.

La incapacidad de pagar los sueldos de los funcionarios del Estado, que permitió el desarrollo de los demás mecanismos de pago, facilitó, como ya se mencionó, la formación de un mercado de deuda, que incorporó la tierra como valor de cambio. En medio del desarrollo de una economía de capital basada en el café, 
la posibilidad de negociar tierras resultó de gran importancia. En ese sentido, la utilización de todos estos factores en conjunto posibilitó no solo el pago de los sueldos, sino la incorporación de muchos sectores sociales al ámbito del Estado, subordinando actores importantes y atrayendo grupos económicos, convenciéndolos de la necesidad de establecer un gobierno central capaz de regularizar las acciones de los mercados de deuda, tierra y café. Sin embargo, por importante que esto sea, no debe distraernos del hecho de que este mecanismo forma parte de una estrategia mayor, donde lo político y lo económico están plenamente vinculados, por lo que no puede privilegiarse solo el aspecto económico.

En medio de este proceso resultó de especial importancia la configuración de oficinas capaces de supervisar, fiscalizar y controlar estos procesos. No obstante, ante lo inestable y contingente de las condiciones políticas y las cambiantes circunstancias de este mercado, así como la carencia de poder efectivo en muchas ocasiones, el tipo de funcionario no podía ser un "experto" en los elementos técnicos de las oficinas de Hacienda, que no estaban plenamente definidos o que cambiaban constantemente. La mayoría de los funcionarios tenían, en cambio, conocimiento sobre las normas que regían informalmente a la sociedad, por lo que, aunque la legislación guiaba en dirección contraria, muchos de estos no tenían educación formal, sino que eran parte importante de las estructuras locales. Lo cual no representó una debilidad, sino una fortaleza para la conformación de una administración central. Lo que distingue los casos de Costa Rica y Guatemala es que la extensión territorial era mucho mayor en el último caso, lo que obligó a una jerarquización más amplia que generó a su vez cadenas de mediación más extensas, que muchas veces respondían a intereses regionales (Sarazúa, 2013).

Como puede derivarse de lo mencionado hasta este momento, había pocas personas capaces, poseedoras de conocimiento técnico suficiente para hacerle frente a las necesidades de una oficina pública. No obstante, estas oficinas operaron precisamente por la existencia de personas con conocimiento en el funcionamiento diario de los negocios públicos (locales). En ese sentido, se puede argumentar que el proceso de formación de la burocracia en Costa Rica lidió no solo con la construcción de los procedimientos necesarios en cada oficina, sino que, además, muchos de los mismos procedimientos son un derivado, cuando no una incorporación, de la costumbre a las normas de la oficina, de las formas de resolución diaria de los problemas presentados a la acción estatal en el plano de lo local. 
Las transformaciones en la estructura administrativa y las representaciones de la burocracia, a partir de la década de 1840, fueron consecuencia de una profunda discusión sobre las bases del proyecto político en el territorio de Costa Rica. Debate que se concentró desde un principio en la definición de una autoridad política: quién y cómo debía regir el gobierno dentro de las fronteras del Estado. Esta definición conllevó de manera progresiva la conversión de la costumbre en derecho, haciendo del gobierno el único ejecutor y respaldo de la ley, y en ese sentido cimentando su propia autoridad. Este aspecto es central, ya que existía el consenso de que costumbre y leyes civiles "son a su vez una copia imperfecta de las leyes naturales dadas por Dios a los hombres y las sociedades" ("Influencia de las costumbres sobre las leyes", en La Crónica de Costa Rica, 17 de marzo de 1858: 3-4).

Por ende, aunque las leyes combatieron repetidamente la intervención de los funcionarios en el mercado, en el comercio o los excesos de la explotación de rentas, las costumbres de una sociedad corporativa moldearon las normas de funcionamiento del Estado y su administración. La sociedad costarricense había construido fuertes lazos sociales, económicos y políticos, formales e informales, los cuales proceden de las formas de la sociedad colonial, las cuales no desaparecieron después de la independencia sustituidos por el modelo liberal. Así, en la formación del Estado convivieron distintos modelos, que permiten comprensiones también diferentes de la organización social y política.

Por lo tanto, se afirma que la aplicación de las normas de una sociedad corporativa, no plenamente monetizada, permitió la construcción de un sistema con capacidad no solo de solventar problemas del pago de funcionarios, sino también de consolidar la autoridad central del gobierno, que fue en última instancia lo que movía todo el proceso. Esto no implica que este modelo no chocara con las ideas liberales de economía política más en boga, sino que la aplicación de dichas ideas se vio moldeada por normas no escritas, procedentes de la costumbre como marco de acción de la vida diaria.

\section{El entramado institucional administrativo de Estado}

en un pueblo ilustrado, la fuerza del poder no está en el poder mismo: ella está en el alma del gobernado. Cuanto más se conoce la fuerza de la autoridad, más se respeta ésta. Se adora en la ley la voluntad general 
("Influencia de la Ignorancia y las Luces", El Costarricense, 11 de diciembre de 1847: 227).

Dicha capacidad, tanto de imponer la voluntad general como de generar la conciencia necesaria sobre la existencia de ese poder, no sería posible $\sin$ la existencia de un entramado institucional administrativo. Este fue construido y reconstruido a lo largo de dos décadas de actividad política, dirigido por una capa de funcionarios estatales, de incipientes burócratas, que permitieron la relativamente rápida consolidación de un cuerpo político estatal en la más débil de las provincias del Reino de Guatemala. Lo anterior resulta de interés, precisamente, por la capacidad de su grupo dirigente de consolidar con relativa rapidez un gobierno estable. Esta característica, posible gracias a un conjunto de factores especiales, entre los cuales se encuentra la existencia de la República Federal de Centroamérica desde 1823, que facilitó la construcción de una administración legal y hacendaria ininterrumpida desde 1821.

Por lo tanto, se hace imposible hablar de la burocracia estatal costarricense sin referirnos a su administración, a la institucionalidad que acoge y transforma las relaciones existentes entre el gobierno, los primeros empleados públicos y los gobernados. La misma que permitió, como consecuencia, la formación de una burocracia más parecida al ideal weberiano a finales del siglo XIX. Por lo pronto, la mayor particularidad del caso costarricense radica en la falta de estructuras administrativas tras la independencia.

En 1821, tras la firma del acta de independencia, el 29 de octubre de ese año, la única oficina administrativa de peso en la provincia era la administración de tabaco, conocida como el estanco de tabaco (Rodríguez, 2014: 188-191), la cual respondía directamente a la superintendencia de tabaco ubicada en Guatemala que, en última instancia, controlaba su siembra, producción y comercialización (Aldave, 2008). El gran reto de los dirigentes de la provincia era construir una administración estable, prácticamente de la nada. Para ello contaban con el vago conocimiento que tenían sobre las estructuras hacendarias, políticas y legales del Reino, así como con la experiencia ganada por sus representantes en las Cortes de Cádiz (Fernández, 2005; Obregón, 2013).

Aunque, fue finalmente la existencia de la República Federal de Centroamérica la que daría un rumbo definido a dicha administración. Como lo apunta Arturo Taracena: 
porque hubo práctica política republicana desde 1823-1824 es que Costa Rica y los demás países centroamericanos pudieron existir como entes políticos diez, veinte o más años después, en un periodo que se extiende entre la ruptura del pacto federal (1838) y el decreto respectivo de la República indivisa, centralista, pues el ejercicio de la soberanía no emanaba de la previa existencia de la nación como tal, sino de los representantes escogidos selectivamente para hacer funcionar el régimen republicano (Taracena, 1996: 155-156).

Una comparación de las medidas tomadas por las administraciones de Braulio Carrillo (1835-1837, 1838-1842), uno de los políticos más renombrados del periodo formativo del Estado de Costa Rica, y las leyes y reformas del jefe de Estado de Guatemala, Mariano Gálvez (1831-1835), o incluso de las medidas del presidente de la República Federal, José Francisco Barrundia (1829-1830), puede demostrar la enorme influencia que la República Federal tuvo en la conformación de la administración y el gobierno de Costa Rica. Un solo vistazo a la evolución de los esquemas institucionales del Estado costarricense (esquemas 1 y 2) permite reconocer las particularidades y la rapidez de ese proceso. Los primeros experimentos administrativos se dieron de la mano de la elección de miembros para las diferentes Juntas Gubernativas (1821-1825), las cuales eran el brazo ejecutivo de un Congreso de Representantes de los pueblos de la provincia, que tenía todo el poder al ser la fuente de legitimidad del nuevo pacto.

Estos primeros cuerpos, conformados por siete miembros, se dividían las funciones rectoras de la administración en subjuntas de dos o tres individuos, los cuales debían velar por la recaudación hacendaria, la economía, la política y la policía pero, sobre todo, por las relaciones entre los pueblos dentro de las fronteras de la provincia, actuando como un mediador entre partes, sometido en última instancia a las decisiones y la voluntad de estos. El pacto político en Costa Rica se caracterizó inicialmente por su relación horizontal entre las cuatro principales ciudades del Valle Central (Cartago, San José, Alajuela y Heredia), un espacio intermontano de $1000 \mathrm{~km}^{2}$ donde, desde finales del siglo XVIII, se había conformado una comunidad de intereses, la cual se definió por su deseo de mayor autonomía con respecto a los centros de poder: León, en Nicaragua, y Guatemala.

La independencia no fue nunca parte del proyecto político del grupo dirigente costarricense, que desde finales del siglo XVIII deseaba obtener autonomía dentro del régimen colonial español. En otras palabras, deseaban conseguir una mejor posición comercial que les permitiera hacer buenos negocios, no la in- 
dependencia (Rodríguez, 2014: 171-173). A partir de lo anterior, se asume que la emancipación en Centroamérica fue una consecuencia de la convulsión sociopolítica mexicana en ese mismo periodo, en relación con el imperio (Vásquez, 2004), lo cual a su vez condujo a la desestabilización inicial de la región, cuyas consecuencias bélicas Ilevaron al final de la República Federal, un poco más de una década después.

Esquema 1. Evolución de la institucionalidad costarricense entre 1823 y 1825.

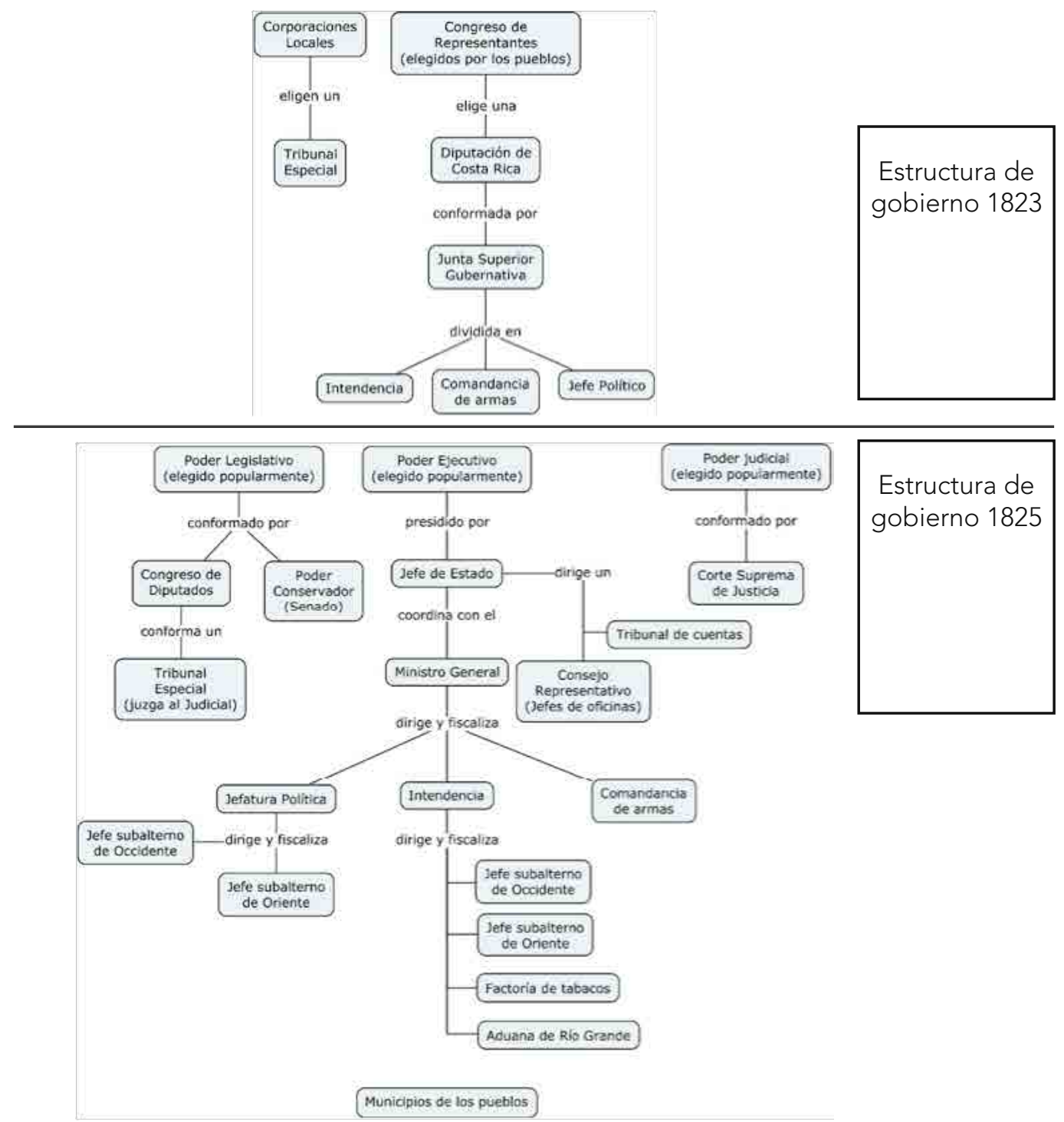

Fuente. Obregón, 2007, vol. 1: 94-96, 125-130, 135-141; Obregón, 2007, vol. 2: 6889; "Decreto XVI", en CLYD, 1824: 34-35; "Decreto XLVI", en CLYD, 1825: 132-133; "Decreto XLVII", en CLYD, 1825: 139-141; "Decreto LV", en CLYD, 1825: 149-151. 
Esquema 2. Institucionalidad costarricense en 1830.

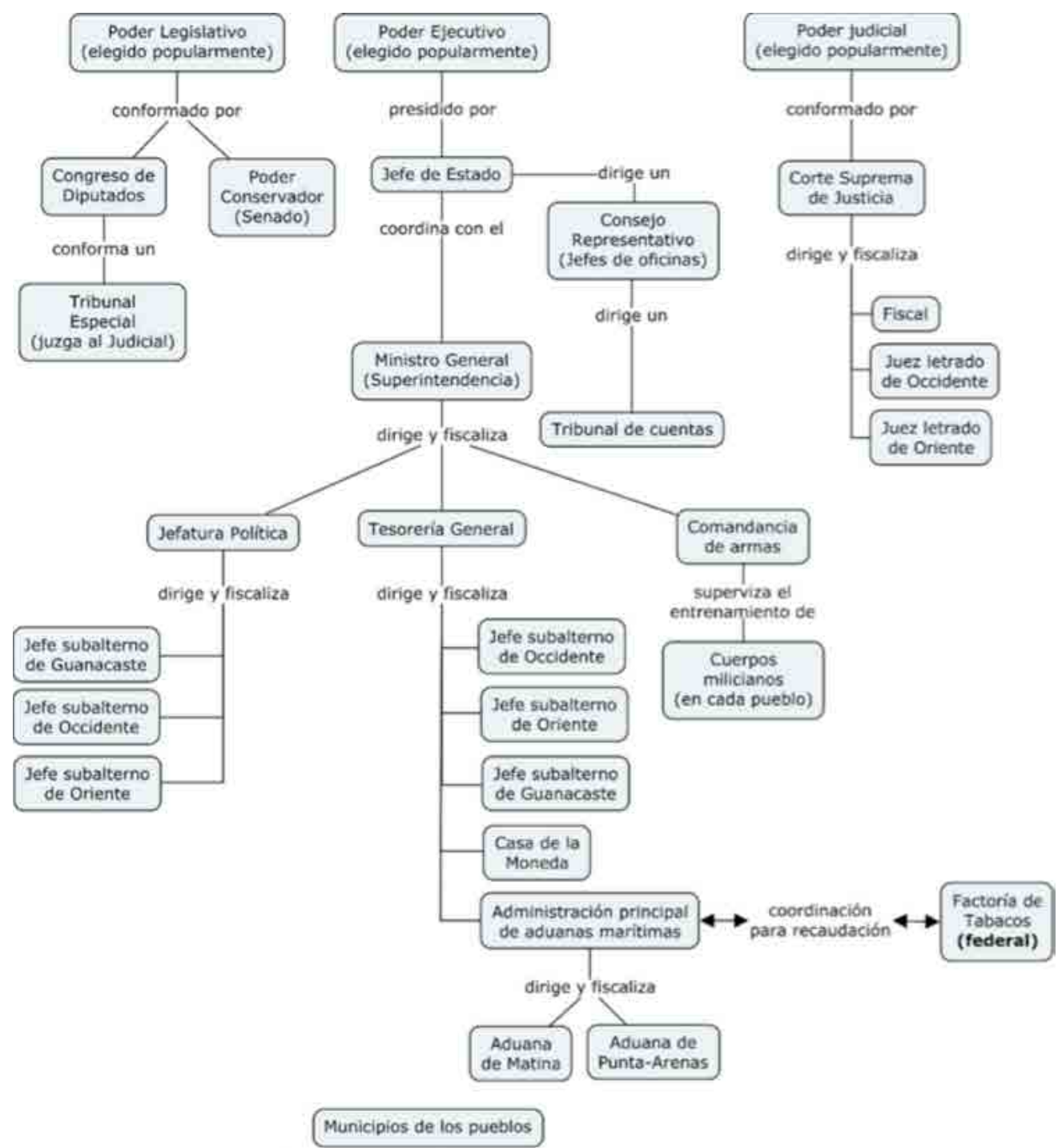

Fuente. "Decreto LXXX", en CLYD, 1826: 197-209; "Decreto CVII", en CLYD, 1826: 261-273; "Decreto 146", en CLYD, 1827: 49-51; "Decreto 154", en CLYD, 1828: 66-67; "Decreto 168", en CLYD, 1828: 100-102; "Decreto 169", en CLYD, 1828: 102-103; "Decreto 171", en CLYD, 1828: 106-115; "Decreto 190", en CLYD, 1829: 141-143; "Decreto 191", en CLYD, 1829: 143-157.

Así, en el periodo entre 1821 y 1825 se materializaron una serie de condiciones que marcaron profundamente el rumbo de los primeros 30 años de funcionamiento estatal, al definir un pacto político donde los ayuntamientos tuvieron un poder 
significativo, con una institucionalidad escasa. La lucha por desarrollar instituciones adecuadas, entre 1821 y 1848, estuvo signada por la imposibilidad de que el gobierno central pudiera imponerse de manera inmediata a los ayuntamientos, a la Iglesia y a otros competidores dentro de las fronteras del Estado. A partir de lo anterior, el proceso político costarricense estuvo marcado por un amplio nivel de negociación que no excluye la violencia como un medio de disuasión.

Lo anterior se manifestó en tres situaciones específicas. Primero, los ayuntamientos mantuvieron funciones omnímodas hasta mediados del siglo XIX, e incluso más allá de 1870, especialmente en los renglones de recaudación y justicia. Segundo, la recaudación estatal, en estas primeras décadas, fue siempre proporcionalmente mucho más baja que la de sus vecinos centroamericanos. Esto se debió a la dependencia que el gobierno tenía de los municipios, así como de un entramado de oficinas basadas en sistemas de recaudación que permitían la explotación de esta por parte de los empleados del gobierno. Tercero, la existencia de un sinfín de cajas paralelas de administración que demostraban la incapacidad del Estado de centralizar su hacienda y recaudar adecuadamente (Rodríguez, 2014).

En ese sentido, la mayor transformación institucional, política y económica a lo largo del periodo en estudio procede de la centralización de poder en el gobierno, trasladándolo desde esos municipios y convirtiéndolo en autoridad gubernativa. A partir de lo anterior, podemos establecer también un orden en el desarrollo de las instituciones públicas del gobierno de Costa Rica, derivado justamente de esta competencia. Las primeras instituciones en desarrollarse fueron las hacendarias, desde 1821, seguidas de las políticas y de justicia —a principios de la década de 1840_, para finalmente concentrarse en las instituciones de gobernación — hacia 1848-, momento en el cual el Estado consolida su capacidad de drenar poder desde los ayuntamientos. Como en el caso del resto de la América Hispana, todo este proceso se llevó a cabo de la mano del desarrollo y la consolidación paralela del ejército como actor indispensable. ${ }^{1}$

Como se colige de una revisión de las estructuras institucionales federales (esquema 3), el primer ramo en importancia fue la Hacienda. El peso de la construcción de un entramado institucional gubernativo en América Hispana dependió de la posibilidad de una transición fiscal, que abandonara las bases del sistema colonial, construidas sobre pesados monopolios y cajas descentralizadas, lo que implicó el despliegue de una serie de nuevas oficinas y funcionarios que fueran

\footnotetext{
1 (Véase Garavaglia y Pro Ruiz, 2012).
} 
capaces de recaudar (López-Bejarano, 2013; López-Taverne, 2013; De los Ríos, 2013). En ese sentido, otros autores han sostenido, siguiendo a Charles Tilly o John Brewer (Tilly, 1992; Brewer, 1989), que el peso de los conflictos militares fue el desencadenante de dicho despliegue. En términos generales esto se tradujo en un gasto militar especialmente alto en todos los Estados, lo que demandó mayor recaudación (Pro, 2012). En el caso de Costa Rica esto se traduce en el desarrollo de la administración hacendaria de 1839 (esquemas 4 y 5), que fue la primera codificación normativa de la administración del Estado de Costa Rica.

Esquema 3. Administración de la República Federal de Centroamérica, década de 1830.

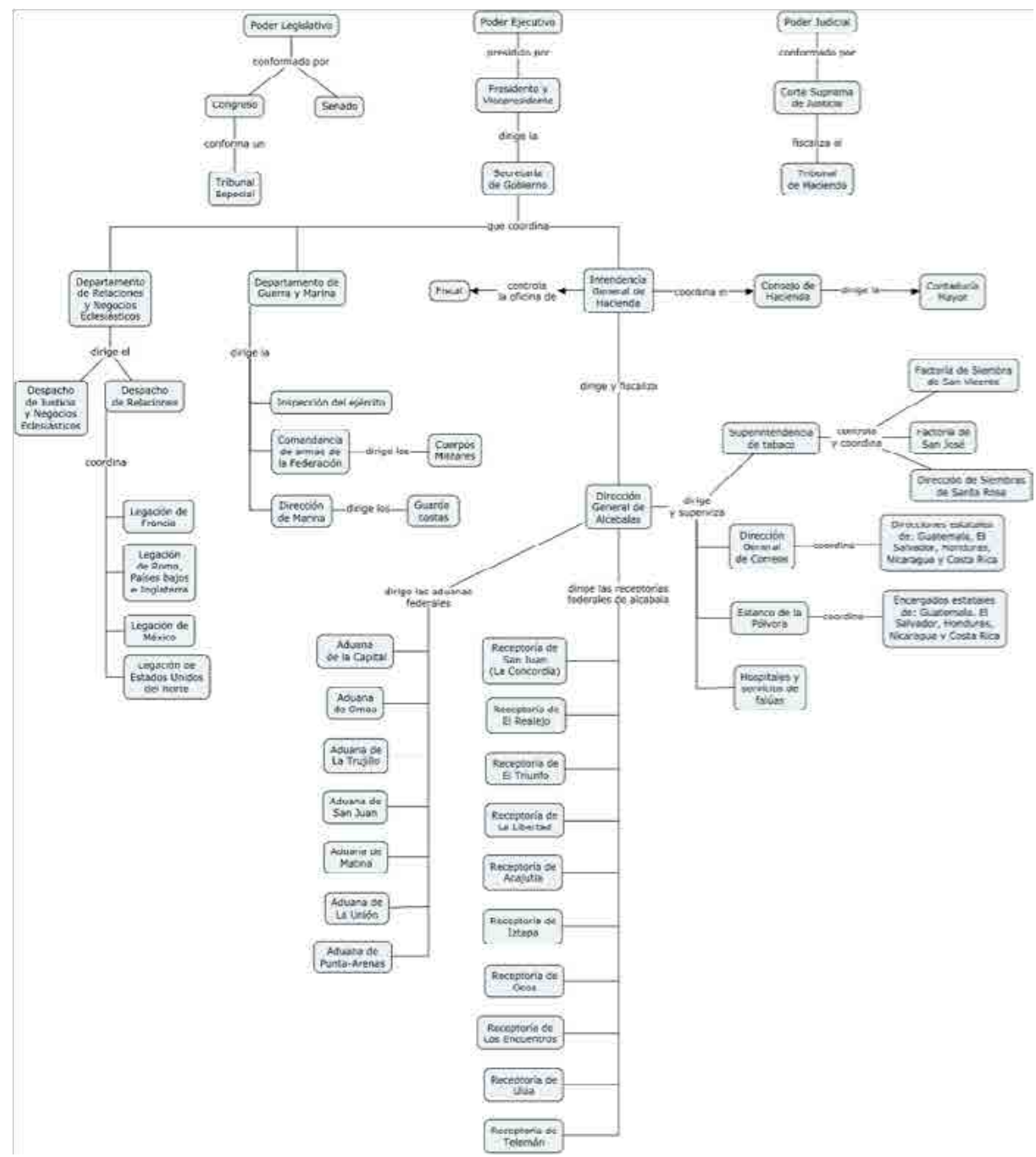

Fuente. Obregón, 2007, vol. 2: 26-32, 36-61; BNG-CV, 1948, hojas sueltas de 1825; BNG-CV, 1953, hojas sueltas de 1830; BNG-CV, 1954, hojas sueltas de 1830; BNG-CV, 1954, hojas sueltas de 1831. 
Esquema 4. Estructura institucional administrativa del Estado de Costa Rica en 1844.

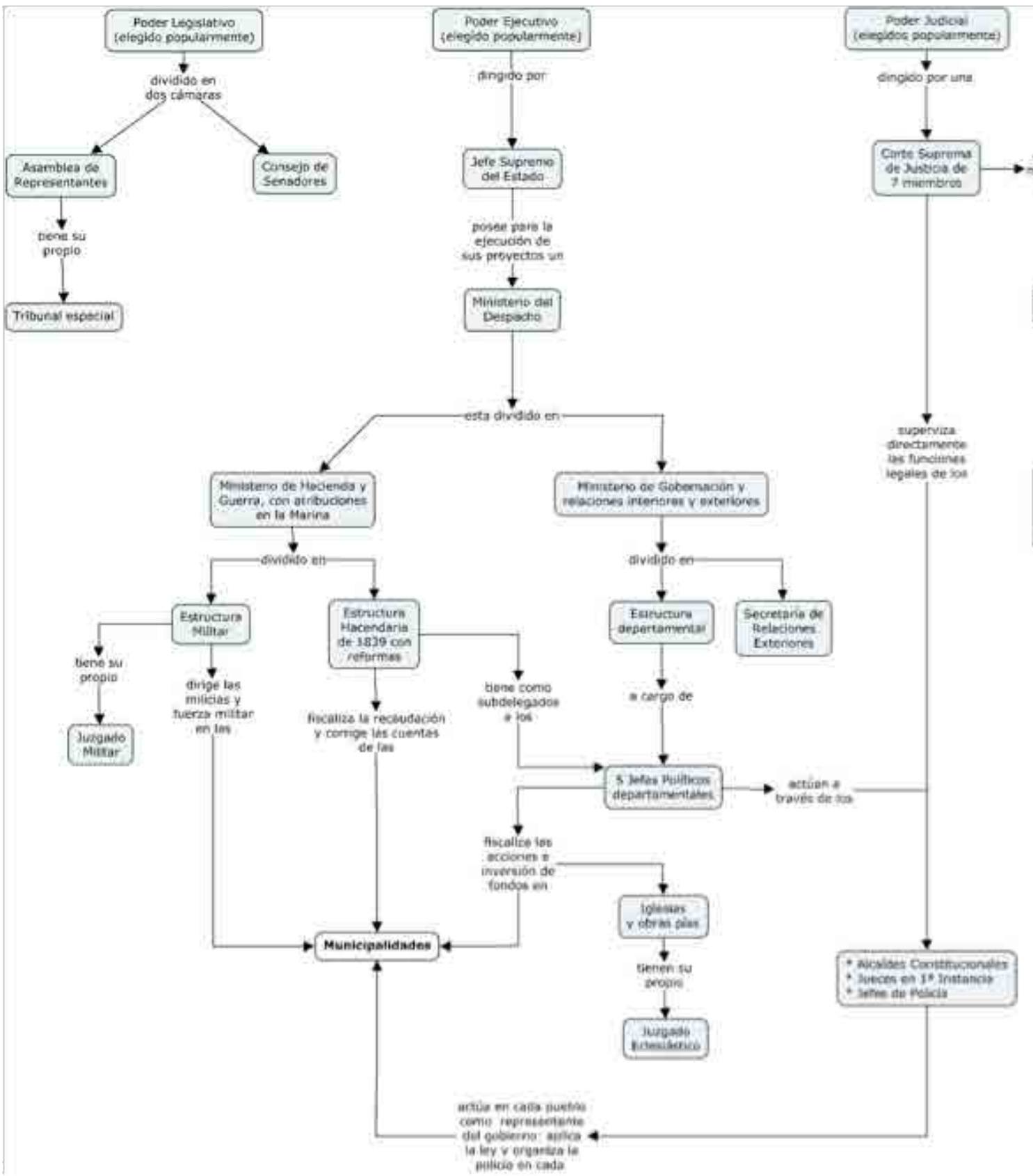

Nota: La estructura de Hacienda puede verse es el esquema 5.

Fuente. Gobierno de Costa Rica, 1839; "Decreto VII", en CLYD, 1841: 44-45. "Decreto XI", en CLYD, 1841: 61-84. "Decreto XXXV", en CLYD, 1841: 136-226; Obregón, 2007, vol. 2: $107-135$. 
Esquema 5. Evolución de la administración hacendaria en Costa Rica entre 1839 y 1858.

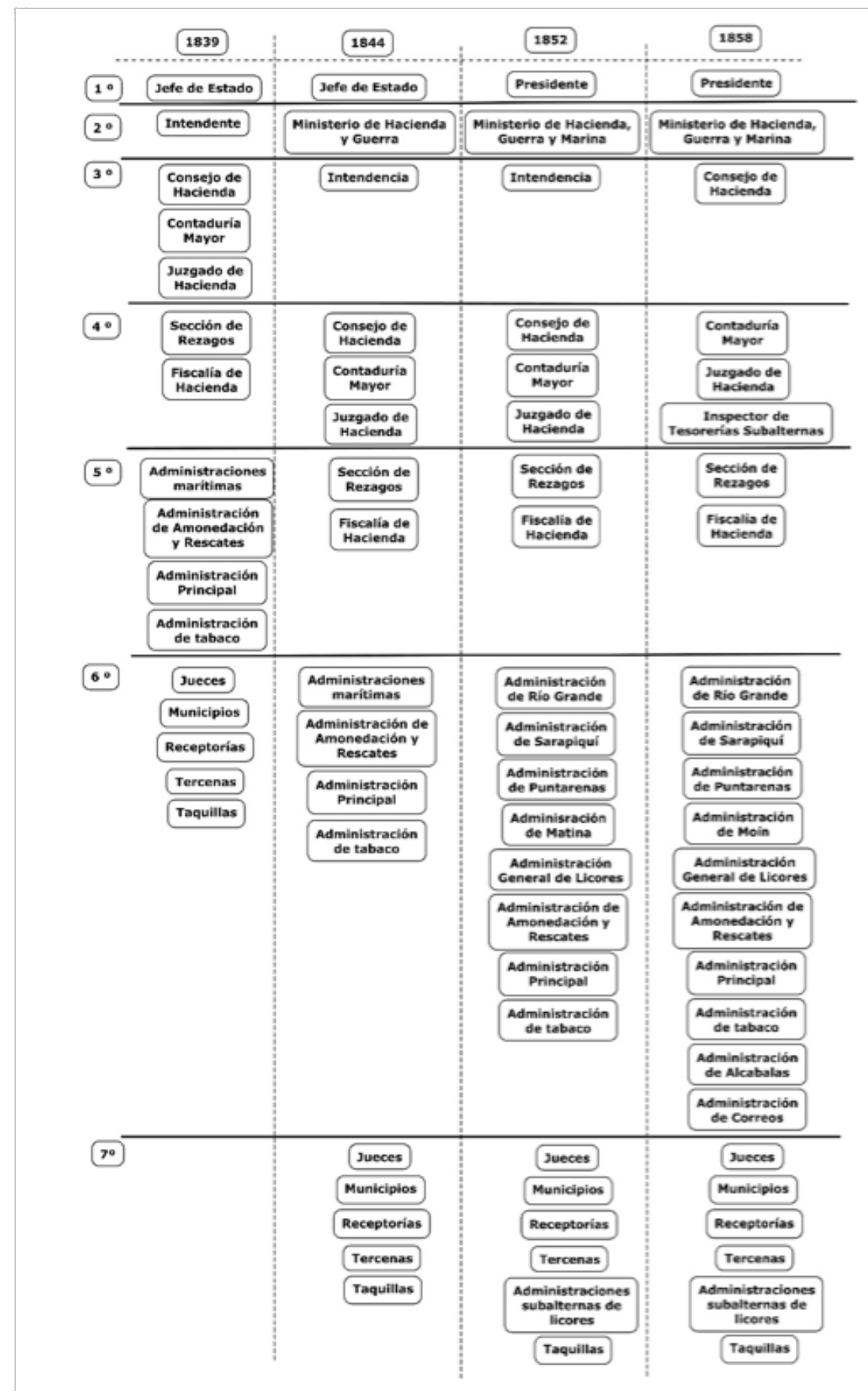

Nota: En este esquema se retratan las instituciones hacendarias y su ubicación general en la administración, no su jerarquía o interrelación.

Fuente: Rodríguez, 2014: 343. 
No obstante, las fuentes de inestabilidad política que cimentaron el crecimiento de la institucionalidad hacendaria en el Estado costarricense no se debieron a guerras contra otros países por la defensa de sus fronteras o para la conquista. En su lugar, fue un proceso dirigido por la necesidad de fortalecer el control interno de la población y definir el rumbo que tomaría el proyecto político, es decir, este fue un camino tomado por circunstancias internas, no externas. ${ }^{2}$ La conformación de un pacto en el país se caracteriza, en estos primeros 20 años, por el conflicto interno en la definición de las bases sobre las cuales se construye su legitimidad. Aspecto que se refleja en la existencia de dos polos: uno basado en la existencia de un proyecto de poder más horizontal, a partir de la rotación de poderes entre las cuatro ciudades principales; mientras que el segundo planteaba un poder más centralizado, con un Ejecutivo fuerte. La máxima expresión de esta condición fue la llamada Guerra de la Liga, que en 1835 enfrentó a las cuatro ciudades y dio como resultado la consolidación de la capital, San José, precipitando las condiciones que permitirían la reforma administrativa de 1839.

En forma paralela, entre 1821 y 1838, la posición del gobierno de Costa Rica con respecto a los conflictos armados regionales se caracterizó por una especie de autoaislamiento, más pretendido que real (Rodríguez 2015). Esta condición, junto con su posición geográfica, alejada del centro político y económico de la zona, hizo que le fuera posible a los dirigentes de Costa Rica concentrarse en resolver problemas internos, mientras actuaban sopesando los resultados de las decisiones tomadas en Guatemala, El Salvador o Nicaragua. Tal como lo señala el ayuntamiento de Alajuela en 1821: "se halla nuestra provincia por su situación local en el feliz goce de ser una observante, expectará (sic) para aprovecharse de lo mejor y más seguro; siendo como lo es actualmente libre" (Ayuntamiento, 1972: 148).

La evolución administrativa del gobierno de Costa Rica es testimonio de esta situación privilegiada, que se manifestó en la existencia de un sistema hacendario que se mantuvo ininterrumpidamente a lo largo de todo el siglo XIX. Esto fomentó un discurso de excepcionalidad entre los políticos, que inventaron una supuesta superioridad moral que les facilitó actuar como una facción propia en el ámbito centroamericano (Rodríguez, 2015). Al defender no solo sus intereses

2 Esto resulta evidente en la mayor parte de los historiadores que han tratado el tema en Costa Rica (Silva, 1994; Gudmundson, 1990). Aunque los conflictos militares fueron en realidad comunes en la primera mitad del siglo XIX, estos siempre revistieron una baja intensidad, siendo muchas veces simples cuartelazos. La amenaza del uso de la fuerza fue, por lo general, efectiva, por lo que la poca intensidad del conflicto ayudó a la continuidad de las actividades económicas y políticas a lo largo del periodo (Corella, 2012). 
económicos, sino su diferencia con respecto al resto de los Estados, los dirigentes costarricenses comenzaron a construir un discurso propio (Acuña, 2002), todavía no uno nacional, pero que funcionaba operativamente en la formación de una estructura gubernativa, siendo además la base del discurso sobre la nación en la segunda mitad del siglo XIX (Molina, 2008; Díaz, 2001).

Como se desprende de los esquemas 4 y 5, y de los párrafos desarrollados hasta ahora, la atención de la organización gubernativa del Estado entre 1821 y 1839 estuvo puesta en la conformación de la capacidad fiscal/hacendaria del gobierno. La Hacienda fue también uno de los principales campos de batalla en el conflicto entre municipios y gobierno central. Una interesante hipótesis para explicar estas características en la formación del Estado de Costa Rica surge de la comparación con el Estado de Nicaragua en el periodo. Víctor Hugo Acuña apunta, siguiendo a Bradford Burns, Knut Walter y Frances Kinloch, que la diferencia entre ambos cuerpos políticos radica en

sus características institucionales, el carácter de sus elites y de determinados condicionamientos estructurales... es posible que la divergencia haya sido consecuencia de que en Nicaragua había más burocracias e instituciones que en Costa Rica; de modo que las elites del antiguo régimen tenían más consistencia y más intereses que defender que las elites de Costa Rica (Acuña, 2014: 16-17)

A partir de 1840 se llevan a cabo importantes codificaciones y leyes que buscaban consolidar el control del ejecutivo sobre la Hacienda. Entre ellas pueden destacarse el cierre y luego redefinición del papel de los municipios, el surgimiento de administraciones como la de aguardiente, que dará paso al monopolio de los licores en la Fábrica Nacional de Licores en 1850, entre otros. No obstante, a partir de esta década comienza a gestarse un cambio en el énfasis de la conformación institucional del Estado, el foco se desplaza progresivamente de las instituciones hacendarias, que siguen siendo las más importantes durante el periodo de estudio, hacia las instituciones políticas, de justicia y las de gobernación o policía.

Como puede apreciarse en el gráfico 2, la importancia de las instituciones hacendarias sigue marcando una tendencia muy importante a lo largo de las décadas de 1840 a 1869. No obstante, la estructura de dicha administración no varía fundamentalmente de la planteada en la reforma hacendaria de 1839. En

\footnotetext{
${ }^{3}$ La elite costarricense estaba más ocupada en crear un frente político común para el comercio.
} 
ese sentido, las instituciones creadas cumplen el objetivo de reforzar las metas propuestas por el plan original: mejorar la recaudación, fiscalizar el cobro y el uso del dinero - dentro de lo cual toma particular fuerza el control sobre los municipios-y determinar las reglas del comercio. No obstante, ya comienza a desarrollarse un importante sector de instituciones de justicia y policía desde principios de la década de 1840, marcado por el Código General de 1841 y por la Ley de Régimen General de las Provincias, que se promulgó en 1848, justamente en el año en el que se declara la existencia de la República de Costa Rica ("D. CLXXIII", en CLYD, 1848: 465-492).

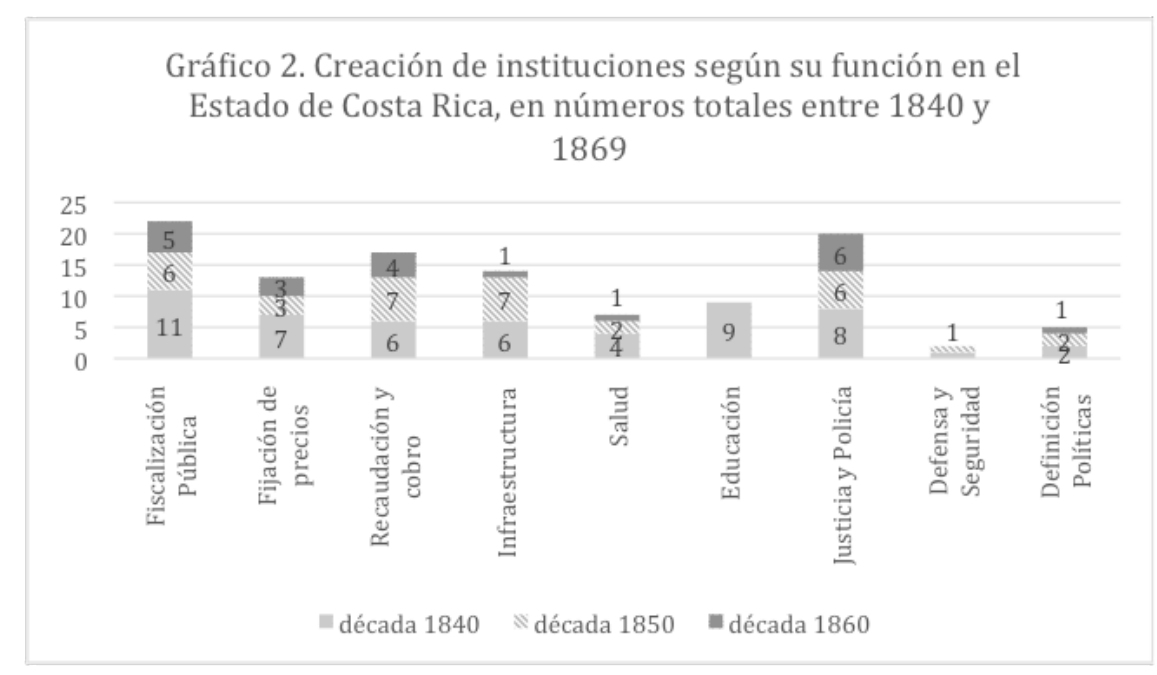

Fuente: Programa, 2017.

Las instituciones de recaudación aumentaron su papel en la década de 1850, aunque, en general, se puede señalar que el movimiento de la administración se inclina hacia una leve disminución en la creación de instituciones de Hacienda, mientras que las de policía y justicia comenzaron a aumentar en cantidad y tamaño. Esta conclusión se refuerza en el gráfico 3, que muestra la importancia porcentual de cada tipo de institución, pero también la intensidad de dicho proceso, el cual se concentró principalmente en la década de 1840. Como se señaló previamente, todo el desarrollo del entramado institucional-administrativo se llevó a cabo de forma paralela con el de las instituciones de defensa y seguridad. El ejército, a pesar de no enfrentar desafíos internacionales, siguió siendo un elemento clave en la conformación del proyecto político, no como institución de control per se (Corella, 2012), sino como institución "educativa", que formaba a los ciudadanos en las normas de disciplina y respeto a la autoridad política y su defensa. 


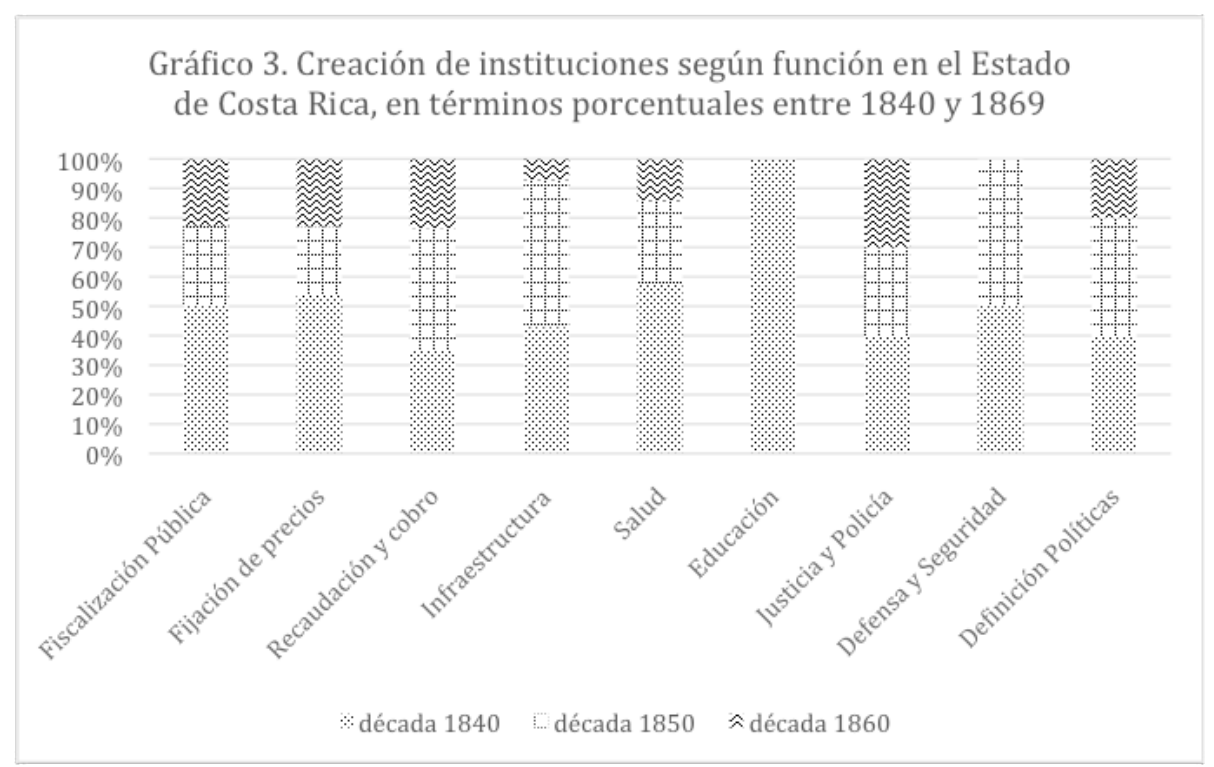

Fuente: Programa, 2017.

Los datos presentados no permiten apreciar en primer plano una transformación muy pronunciada, pero los desglosados nos facilitan observar un cambio que va más allá de la creación de instituciones. En este periodo cambia la percepción sobre la organización del Estado, que se traduce en la construcción de un nuevo entramado de justicia y policía, el cual define la especialización de las funciones administrativas, una delimitación jurisdiccional de la autoridad gubernativa. Esto significó la delimitación más detallada de las funciones de cada oficina, lo cual permitía alcanzar la especialización de la labor pública.

Según los datos recaudados a partir de los presupuestos y de las leyes de salarios, la cantidad de empleados públicos pasó de 77, en 1843, a 909 en $1864 .{ }^{4}$ Antes de señalar conclusiones sobre los datos es importante explicar la gran diferencia en los números. Un primer factor es la capacidad de realizar censos confiables. En 1864 el Estado tenía la capacidad de realizar mejores registros ese fue el año del primer censo oficial-. Un segundo factor es la mejor definición de la categoría de funcionario público, en la cual comenzó a tomarse en cuenta a los empleados municipales y a otros que no eran considerados en la década de 1840. Y para finalizar, el factor del crecimiento mismo de la institucionalidad estatal, que obligó a la contratación de muchas personas para cumplir sus destinos en las nuevas oficinas.

${ }^{4}$ (<http://ccp.ucr.ac.cr/bvp/censos/1864/index.htm>). 
Tomando en cuenta las advertencias anteriores, nos interesa la cantidad de funcionarios de la Hacienda pública, a partir de la cual nos daremos cuenta de las características de lo descrito hasta ahora. Entre 1841 y 1843 había 55 en las oficinas de Hacienda, representando 71.42 \% de los empleados públicos en el Estado. Mientras que en 1864, ante una cantidad de 909 funcionarios en general, había 123 trabajando en la Hacienda pública. Si bien esto implica un aumento de $124 \%$ en la planilla de las oficinas de Hacienda, también evidencia que en el periodo en estudio el peso relativo de estas oficinas en el conjunto del gobierno se redujo hasta $13.53 \%$.

El aumento más significativo de las planillas no estaba orientado a las oficinas de recaudación o fiscalización, a pesar de representar la mayor cantidad de instituciones creadas en el periodo. Las instituciones que más aumentaron su tamaño relativo fueron las de gobernación —donde estaba incluida la policía—y justicia. A pesar de ello, esto no significó una disminución en el peso de la Hacienda en la estructura de administración, ya que la labor de los nuevos policías y jueces estaba vinculada a evitar el contrabando, el cobro de impuestos y alcabalas y otros similares. Esto facilitó la delimitación jurisdiccional de las oficinas administrativas, que seguían orientadas principalmente a la recaudación.

El Estado de Costa Rica se hizo progresivamente más eficiente en el cumplimiento de la tarea de financiar su funcionamiento (gráfico 1). Lo anterior se debe a que el aumento en la planilla estatal se realizó en las oficinas de policía y mando político (gobernadores, jefes políticos, alcaldes, jueces, etc.), con lo cual se reforzó la capacidad del gobierno de imponer su poder y autoridad. Los funcionarios de Hacienda no tuvieron que preocuparse más por ser jueces o policías, sino que, progresivamente, se especializaron en su labor contable, de recaudación o de control. De esta manera la delimitación jurisdiccional de la administración permitió un funcionamiento más efectivo, que se tradujo en un aumento de la recaudación, alimentando de nuevo el despliegue de las oficinas del Estado sobre el territorio.

\section{La legitimidad burocrática: el marco legal de la reforma administrativa}

De nada sirven las mejores leyes si no tienen cabal ejecución. Y si el Gobierno, consultando el bien presente y la creación de los mejores elementos para lo porvenir, invierte una gran parte de las 
rentas nacionales en difundir, de la manera más amplia la enseñanza primaria y la secundaria, la autoridad no debe ser menos celosa en evitar que la juventud se corrompa, malogrando legítimas esperanzas ("Circular I", en CLYD, 1880: 1-2).

El funcionario que no sirve con la pureza, inteligencia, actividad y zelo [sic] que corresponde, es punible y que el que desempeña bien sus funciones no hace otra cosa que cumplir con su deber, salvar su responsabilidad y devengar justamente su sueldo, sin que por esto sea acreedor a una gracia singular (ANCR, Congreso, sig. 5465, ff. 9-10).

Hasta las reformas de 1839 y 1841, en Costa Rica, el marco legal que cimentó las bases de la legalidad de los gobiernos y los pactos políticos fueron los reales decretos y leyes españolas, así como las modificaciones introducidas a partir de Cádiz. En materia de Hacienda, por ejemplo, la Ordenanza de Intendentes de Nueva España se mantuvo como la máxima normativa del Estado, hasta que fue sustituida por el Reglamento de Hacienda de 1839. Las primeras Juntas Gubernativas y las constituciones de la provincia fueron influidas por las disposiciones de Cádiz, incluso por la estructura de las diputaciones del periodo gaditano. Tres principios político-hacendarios fueron centrales en este proceso: la centralización de caja, que busca la concentración de riquezas para su mejor manejo, y permite el uso de los presupuestos como herramienta de política fiscal; la legalización fiscal, la cual afirma la necesidad de que todas las normas que afecten la recaudación y el gasto público deben ser aprobadas por una autoridad legítimamente establecida; y el principio de la división de poderes, que es complementario y una consecuencia de los dos anteriores (Rodríguez, 2014).

Un estudio inicial de la legislación del Estado de Costa Rica hace posible una recomposición de la organización institucional de la administración, así como sus cambios y características. No obstante, un análisis crítico profundo nos revela mucho más. A través de las leyes es perceptible el enfrentamiento entre la costumbre y la norma escrita en la composición de las oficinas públicas y, con esto, de la legitimidad misma del accionar del gobierno. La forma de las leyes y sus objetivos nos muestran, en la práctica, de qué manera la conformación de una burocracia estatal está ligada con la consolidación del Estado. 
Entre 1821 y 1858 la transformación de las instituciones gubernativas evidencia las características del proceso de conformación estatal, el cual comenzó por la Hacienda y los medios de coerción, para desplazarse hacia la justicia y los mandos políticos, con el fin de fortalecer un proceso de especialización jurisdiccional, orientado a la concentración de poder trasladándolo desde los municipios y otras instituciones en los planos locales. Esto se observa, en forma general, en el aumento constante de la cantidad de funcionarios y la concentración o diversificación de sus funciones. Pero es la relación entre empleados públicos y las oficinas del gobierno, entre los funcionarios y las instituciones que debían servir, lo que marca uno de los elementos centrales de esta transformación.

Hay al menos tres aspectos legales claramente definidos en la legislación costarricense, sobre la administración de las oficinas públicas a finales del periodo en estudio. El primero, que los empleados públicos no pueden ni deben usurpar la autoridad del Estado, ellos responden a una cadena jerárquica, tienen funciones y deberes específicos que no les permiten atribuirse la capacidad de hablar en nombre del Estado, aunque sean, en sí, representantes del gobierno. Segundo, los funcionarios deben atender al exacto cumplimiento de sus responsabilidades para con su oficina, así como con las ordenes que se les impartan, para lo cual resulta de mayor importancia el conocimiento que la experiencia técnica. ${ }^{5}$ Tercero, las personas que sirven en las oficinas del gobierno representan al Estado, por lo que fueron elegidos para cumplir un destino superior, lo cual les impide aprovecharse de su cargo para hacer ganancias indebidas, pero no los separa de su rol como individuos con intereses privados en el conjunto de la sociedad y de la economía.

Como es de suponer, el proceso de control en la provincia de Costa Rica comenzó por la única oficina existente en la época, la Factoría de Tabaco. Así, el 29 de octubre de 1821, el mismo día en que se firmó el acto de independencia, el ayuntamiento de San José advirtió al factor de tabacos, encargado de dirigir la oficina, que no debía entregar dineros de la caja de esa oficina a nadie si no era

\footnotetext{
${ }^{5}$ Esta distinción sigue la discusión sobre la diferencia entre techne - asociada a la experienciay conocimiento — como sabiduría práctica—. La primera es entendida por Steven Smith, siguiendo a Aristóteles, como "la ordenada, metódica aplicación de inteligencia a algunos problemas para el beneficio de ganar control sobre futuras contingencias" (Smith, 1989: 137). Por su parte, el conocimiento puede ser asociado, según Carl Shaw, al concepto de sabiduría práctica de Aristóteles, donde se establece una relación importante entre las "normas universales" y los eventos prácticos, en una forma de jurisprudencia dada por la acción de las personas con su entorno, lo que demanda la acción de la costumbre (Shaw, 1992: 384). Esta precisión resulta central en la polémica sobre los modelos burocráticos de Max Weber y Hegel, a los que se hace un guiño en este artículo.
} 
bajo la autoridad de la junta gubernativa que se debía establecer en la provincia. De lo contrario, "se les hará responsables de la versación y consumo inoficioso, perjudicial y arbitrario que se haga de dichos ramos por otra autoridad o persona" (Meléndez, 1978: 70). Como no podía ser de otra manera, el gobierno de la provincia de Costa Rica trató de asegurar fondos suficientes para permitir la formación de un nuevo pacto.

No "usurpar" la autoridad del Estado significó que los funcionarios no actuaran fuera del poder que les otorgaban las leyes. Esta condición implicó la construcción de un amplio marco legal reglamentario, que definiera progresivamente los deberes y derechos de los empleados en las oficinas. Así, este primer periodo es rico en reglamentos, circulares, acuerdos y otras formas legales destinadas a decirle a los servidores públicos lo que debían y no debían hacer. De nuevo, las oficinas de Hacienda fueron pioneras en el desarrollo de este ordenamiento, no de manera incidental sino, precisamente, por la importancia que estas revestían para el financiamiento de todo el entramado institucional.

Hacerse obedecer era un paso crítico que podría permitir el funcionamiento y la consolidación de la autoridad gubernativa, a través de las oficinas. Crear instituciones y leyes que las respaldaran era de utilidad en la medida que daba un marco legal sobre el cual actuar, con el cual establecer los límites entre las acciones públicas y privadas. En ese sentido, el gobierno del Estado de Costa Rica trató de dar pasos acelerados por definir hasta qué punto podían acercarse ambos planos, ¿hasta dónde los empleados públicos podían actuar en la economía privada y qué les era permitido?

De nada serviría la ley si se transformaba en letra muerta, aspecto que era muy evidente para los dirigentes del Estado, a quienes durante todo el siglo XIX les fue muy difícil imponer una autoridad definitiva que fuera acatada en la práctica. Esto se retrata en un episodio de 1841, cuando el Jefe Político del Departamento de Guanacaste hizo una consulta al Jefe de Estado. Según informaba la autoridad política, tanto los alcaldes como los jueces y otros miembros de las oficinas de gobierno, local y central, se negaban a obedecer sus disposiciones. La respuesta a la consulta fue categórica, por lo cual se le ordenaba que:

en virtud de esta autorización terminante se hará usted respetar y que se respeten y obedezcan sus órdenes: y si alguna persona, Municipalidad o Alcalde las resistiese o despreciase, después de la exacción de la multa, le instruirá causa con que dará cuenta al Gobierno si fuese empleado público ("Resolución II", CLYD, 1841: 125). 
Esto mismo se repitió con los miembros del ejército, ${ }^{6}$ quienes por decretos de 1835 y 1836 debían atender a las órdenes de las autoridades civiles para la construcción de caminos. En 1840 los soldados no obedecieron a los alcaldes, por lo que el gobierno llama al Comandante General a obligar a su cumplimiento, haciendo patente el "desagrado con que el Gobierno ha sabido que (...) son despreciados en los reclamos que las autoridades civiles hacen de ellos" ("Resolución XXI", CLYD, 1840: 293). No es posible determinar con seguridad si las órdenes fueron acatadas al final, pero estas incluían el uso de la fuerza física en caso necesario, lo cual demuestra que el gobierno carecía todavía de la legitimidad suficiente para imponer sus órdenes de manera definitiva, y se volvía entonces más importante el reclutamiento de personas con "autoridad" en las dinámicas sociales y económicas locales, obligando al gobierno a negociar y captar a estos individuos en la administración, aspecto que resulta clave para comprender el tipo de burócrata incorporado en estas primeras etapas de formación del Estado.

Este y muchos otros ejemplos demuestran el complejo proceso de conformación de la autoridad gubernativa del Estado. Por un lado, la subordinación de los empleados públicos a sus oficinas y labores, que requería un proceso de convencimiento, pero también de coerción. Por otro, la competencia de algunas instituciones y cuerpos que detentaron su propia cuota de poder, sustentado en la costumbre del marco legal español y las normas sociales y culturales de la coIonia, tales como la Iglesia o los ayuntamientos. Resolver la competencia interna de otras instituciones (Iglesia, municipios, corporaciones profesionales y otros) se convirtió, como se dijo páginas atrás, en uno de los principales retos del gobierno y de los motores de su consolidación.

El establecimiento de estrictas normas legales y estructuras burocráticas, primero en la capital ${ }^{7}$ y luego en el resto del territorio, fue una consecuencia de dicha competencia, cuyo aspecto más visible fue la transformación del entramado institucional burocrático, que definió el papel de los empleados públicos con

6 Se ha enfatizado que durante gran parte del periodo en estudio la institución militar se compuso de algunos cuadros de comando, quienes eran soldados de experiencia, y un cuerpo estable de milicia que rotaba de manera regular (Corella, 2013). No se trata de soldados de carrera, sino de ciudadanos del Estado que mediante la rotabilidad podían acceder a los ejercicios militares, los cuales facilitaban la enseñanza de disciplina y de orden jerárquico que facilitó la consolidación del orden gubernativo del Estado.

7 Debe recordarse que el reducido tamaño del territorio efectivo del Estado de Costa Rica facilitó la comunicación, haciendo que la concentración de las dinámicas institucionales en San José no se convirtiera en un problema serio. 
respecto a las oficinas. La primera codificación de importancia se encuentra en el Reglamento de Hacienda de 1839, el cual planteó las primeras normas en ese sentido. Cada una de las oficinas de la Hacienda (esquema 5) recibía una cantidad de personal adecuado y funciones nuevas, delimitadas y reglamentadas. Pero lo más importante de esta reforma fue darle a la función estatal un ámbito mucho más claro de acción, construyendo un carácter propio de lo "público" que lo diferenciara de su entorno más inmediato.

El trabajo en una oficina pública debía constituirse en una labor regulada, que distinguiera la importancia y la responsabilidad de las obligaciones que en ella se cumplían. Esto también implicaba reconocer una naturaleza "diferente" en el empleado público, por el bien de la "patria", que debía hacer de su trabajo su vida, la cual era el reflejo de la voluntad del pacto político; era un representante del Estado. Ante tal giro, de características weberianas, se comenzó a regular la actividad burocrática y a definirse las condiciones del trabajo.

Se estableció que, para cualquier persona, la estabilidad del empleo en las oficinas de Hacienda se mantendría "mientras durara la buena conducta del que los sirve", que tras 20 o 30 años de labor honrada podía darle derecho a una pensión (Gobierno, 1839: 21). La posibilidad de retiro significaba una profunda diferencia con respecto a la idea de una burocracia prebendaria colonial (Burkholder y Chandler, 1984), desarrollada antes de la Independencia, pero que tenía profundas raíces en las primeras décadas posteriores. No obstante, estas reformas fueron acompañadas de otras igualmente importantes: exámenes para conocer las habilidades de los empleados, horarios de oficina, regulaciones para la existencia de vacaciones y un marcado orden jerárquico.

Todo comenzó por las oficinas de Hacienda, para trasladarse progresivamente al resto del gobierno. Los administradores eran los jefes inmediatos de cada oficina ("Decreto CVIII", CLYD, 1846: 382-383), principio que buscaba crear una cadena de mando para su funcionamiento, pero principalmente para la vigilancia del cumplimiento de las normas consideradas de "servicio público", y que eran exigidas a todo funcionario. Entre ellas se encontraban: la puntual asistencia a los horarios, la limpieza de la oficina, el cuidado y resguardo de la labor encomendada y de los archivos de la oficina. Pero en última instancia todas dependían directamente del intendente general "en todo lo directivo y económico, traslación de caudales, libramientos, etc."; asimismo, las dudas sobre procedimiento debían ser consultadas a ese funcionario ("Decreto CVIII", CLYD, 1846: 383, 386). 
En 1841 se estableció un orden jerárquico vertical para la comunicación de la información, lo que debía facilitar la imposición de la autoridad gubernativa desde la cabeza hasta los ciudadanos. Una parte del mandato establece, tras hablar de los altos mandos, que

Los Jefes Políticos practicarán (las comunicaciones) entre los empleados Eclesiásticos de su Departamento, Jueces de $1^{\text {a }}$ Instancia y Alcaldes Constitucionales y de barrio: el Intendente, a todas las oficinas de Hacienda; y el Comandante General, a los puertos, fronteras y de plaza, y a los Sargentos mayores y ayudantes. Los Jefes Políticos son obligados, bajo su responsabilidad, a hacer la circulación inmediatamente, y la publicación en cada uno de los pueblos de su Departamento, en el primer día festivo, a las nueve de la mañana ("Orden VII", CLYD, 1841: 55).

Esta lógica fundamental, que pretendía cimentar las bases del accionar gubernativo, con legitimidad y control, se reproduce en la forma del juramento constitucional en esa misma década. Partiendo del Jefe de Estado, se toma juramento a los ministros y estos a sus empleados, creando una cadena vertical que pretende garantizar el mantenimiento de dicho orden. No obstante, a lo largo de la década de 1840, en la medida en que se definía la centralización del pacto político y se establecían los límites jurisdiccionales de las oficinas del gobierno, el foco fue desplazándose desde el uso de la mera violencia (en la forma del uso de la fuerza física para el cumplimiento de las órdenes del gobierno) hacia la construcción de imagen burocrática del poder.

El objeto que reúne a los individuos de los Supremos Poderes es la Patria, su conservación, su aumento y felicidad, todas aquellas tareas tienden a la consecución de este fin, de suerte que la razón, la justicia y la probidad forman de todos ellos un corazón y este cabalmente es el espíritu público que anima a cada uno de los funcionarios: el buen ejemplo es una fiebre moral que se comunica instantáneamente por el gran poderío de la imitación ("Interior", en El Noticioso Universal, 21 de marzo de 1834: 605-606).

Más allá de cualquier acto localizado en acciones legales individuales, en la década de 1840 la legislación apunta al comienzo de un proceso de control de las voluntades individuales y colectivas. Esto estuvo ligado a la idea de un gobierno central cuya legitimidad estaba basada, desde 1821, en el pacto entre los representantes de los pueblos y no en una autoridad o norma ajena. Esta condición hace muy relevante la lucha entre los municipios, no considerados como meros 
localismos, y el gobierno, que al fin y al cabo dependió enteramente de los cuerpos municipales durante este periodo. Como se ha mencionado previamente, el pacto político costarricense implicó la competencia entre "lo local" y "lo central" durante la primera mitad del siglo XIX, aspecto que obliga a considerar la importancia de la formación del entramado administrativo-institucional en esta competencia.

A propósito de esta situación, las palabras de José Luis Vega Carballo, en referencia a la administración de Braulio Carrillo (1835-1837/1838-1842), resultan muy esclarecedoras, al señalar que las municipalidades habían sido sometidas "a vigilancia forzosa por parte de funcionarios especializados de la administración central" (Vega, 1981: 78). El desarrollo constante de dicho entramado comenzó a envolver rápidamente las competencias de aquellas instituciones e individuos que podían reclamar poder propio dentro de las fronteras del Estado, acabando con la competencia. Esto, esencialmente, parece marcar un derrotero diferente al seguido por el Estado de Guatemala, que tuvo que aprovechar la existencia de los lazos socioeconómicos "informales" que ligaban a las elites regionales con la de la Ciudad de Guatemala, para sobrellevar la negociación entre lo local y lo central en la formación de su gobierno (Grandin, 2000). Esto no implica que el Estado de Costa Rica no hiciera uso de los mismos medios, pero es la forma y sus fines lo que produce una marcada distinción en ambos casos.

A partir de la década de 1840, en el gobierno del Estado de Costa Rica se desarrolló la idea del funcionario-educador. Este se encontraba en la posición de guiar a partir de la enseñanza de los principios de civilidad y obediencia a la autoridad. Se consideró que esto formaba parte de la consolidación del prestigio del gobierno, una fuerza que debía actuar como un verdadero capital moral que facilitara la aplicación de normas y su cumplimiento. Así, "el prestigio del gobierno es un verdadero capital, que como todos los capitales que están basados sobre la confianza, como el crédito, está sujeto a las alternativas de la alza y baja. [...] El prestigio del gobierno es, en suma, un capital moral" que sienta las bases de una administración y de un modelo político basado en la transmisión de autoridad desde lo local hacia lo nacional ("El principio de Autoridad de A. M. Troplong", Boletín Oficial del Gobierno de Costa Rica, 12 de noviembre de 1856: 527).

Como representantes del Estado, los funcionarios actuaban como agentes de ese poder moral, que poseía el respaldo de la fuerza coercitiva. Por consiguiente, la lección que la burocracia estatal debía impartir "tiene por objeto formar las buenas costumbres, combatir las pasiones i sujetar el ejercicio de los órganos a 
ciertas reglas i condiciones i este aprendizaje corresponde de preferencia a los pueblos que como el nuestro comienzan la carrera de la civilización" ("Educación Pública", en El Costarricense, semanario oficial, 5 de agosto de 1848: 460). Situación que posee profundas ramificaciones en la percepción sobre los funcionarios del Estado y el servicio público, pero también sobre el papel del gobierno en el conjunto social.

\section{Conclusión}

Hay una profunda necesidad de revisar las bases sobre las cuales se ha pensado la formación del Estado en Centroamérica. La preeminencia de las explicaciones económicas, sobre las políticas y culturales han derivado en una comprensión específica de la constitución del Estado como un fenómeno ligado a la construcción de mercados y al establecimiento del liberalismo como principal orientación política. Esto ha creado una brecha de "dudas sin respuesta" en el análisis de la formación de los Estado en los distintos casos nacionales en Centroamérica. A partir del caso de Costa Rica es posible plantear algunos cuestionamientos interesantes a los límites de esa explicación, principalmente a partir del análisis de las bases sobre las cuales se conforma la institucionalidad administrativa del gobierno y su burocracia.

¿Puede existir una burocracia basada en una lógica diferente a una economía totalmente monetarizada? Si bien, en el caso que se ha analizado, la economía costarricense se encontraba en el camino de serlo, y había desarrollado mecanismos especiales para el pago de los sueldos, esta estaba lejos de lograrlo. Además, no debe escapar al análisis el hecho de que, en última instancia, aunque no fuera intencional, estos mecanismos no eran solo un medio de pago, sino también un intrincado sistema de interrelación social, que usaba la reproducción de la deuda como un mecanismo de control extraeconómico. Sin implicar que esta fuera una estrategia consciente, denota las profundas interacciones entre distintas lógicas de relaciones sociales y su impacto en las estructuras políticas e institucionales.

No se sugiere que deba abandonarse el modelo de Weber, pero sí aplicarse críticamente, revisando otros modelos e ideas, como pueden ser las de Hegel, que plantean una abierta conciliación entre los burócratas en su papel como representantes del Estado y su papel como sujetos privados, poseedores de un 
conocimiento práctico cotidiano. No olvidar la teoría, pero complementarla con un trabajo empírico que nos permita buscar la adaptación de las teorías a las sociedades y no al revés. La conformación de una burocracia en el Estado de Costa Rica parece mostrar la lucha entre dos lógicas legales que parecen contradictorias, pero que sustentaron la acción de los burócratas a lo largo de varias décadas. En ese sentido, la consolidación de una burocracia clásica, de un estilo puro, según el pensamiento weberiano, fue posible hacia finales de siglo, lo que no impide que a lo largo del mismo conviviera con un sistema basado en el derecho natural y la costumbre como base de la sociedad.

El Estado tuvo la suficiente solidez institucional a finales de 1840 como para comenzar a construir un discurso propio sobre el poder. Las instituciones republicanas, de matriz liberal, fueron modificadas por una lógica legal diferente. Todavía es pronto para establecer conclusiones definitivas sobre este punto, falta mucha investigación y debate. No obstante, la lógica que sustenta la institucionalidad, en estas primeras etapas, parece estar más cercana al derecho natural, codificado en el pactismo que fue la base de las acciones del cuerpo político en sus primeras etapas de formación. Esto obliga a pensar el uso de teoría y las perspectivas que se han planteado, ya que otorga un papel preponderante a la costumbre como elemento del discurso y la acción política.

Pero más allá de esta polémica idea, este estudio muestra cómo el Estado en Costa Rica se consolida varias décadas antes de lo que usualmente se ha señalado en la historiografía costarricense, lo cual permite un debate más amplio sobre la posibilidad de comprender el discurso sobre el poder construido a partir de la década de 1840, precisamente ligado a la conformación de la burocracia estatal, como parte de la formación de la nación y no meramente como un discurso protonacional. Esto abre también la posibilidad de considerar a los empleados públicos como burócratas en todo el sentido de la palabra, aunque actuando bajo lógicas diferentes a las usuales.

La consolidación del Estado en Costa Rica responde al proceso de conformación de una autoridad política, no de un mercado, aunque resulte que ambos aspectos estén muy relacionados. Esta consideración nos obliga también a pensar en la consolidación de ese cuerpo político separado de la consolidación de los liberales en el poder. Esto no debe leerse como un desafío a la idea de que el Estado cambió sustantivamente a partir de 1870, con la llegada de los que ha venido a comprenderse con el ascenso liberal, sino que aporta una comprensión 
más amplia del proceso que entrelaza ese momento con una explicación más compleja del proceso de formación estatal.

Finalmente, podemos afirmar que las personas que formaron parte de las oficinas del Estado, a partir de la década de 1840, fueron tanto patriotas como educadores, empresarios y burócratas, sin que esto representara una contradicción de términos.

\begin{abstract}
Abreviaturas
ANCR $=$ Archivo Nacional de Costa Rica.

BNG = Biblioteca Nacional de Guatemala.

CLYD = Colección de Leyes y Decretos del Gobierno de Costa Rica.

$\mathrm{CV}=$ Colección Valenzuela.
\end{abstract}

\title{
Fuentes de consulta
}

Actas del Ayuntamiento de Cartago 1820-1823, 1972, Costa Rica, Ayuntamiento de Cartago, Comisión del Sesquicentenario de la Independencia de Centroamérica.

Acuña, Víctor Hugo, 1995, "Historia del vocabulario político en Costa Rica. Estado, república, nación y democracia (1821-1849)", en Arturo Taracena y Jean Piel (comp.), Identidades nacionales y estado moderno en Centroamérica, Costa Rica, Centro de Estudios Mexicanos y Centroamericanos, Facultad Latinoamericana de Ciencias Sociales (FLACSO).

Acuña, Víctor Hugo, 2005, "Las concepciones de la comunidad política en Centroamérica en tiempos de la Independencia", Trace, 37, pp. 27-40.

Acuña, Víctor Hugo, 2002, "La invención de la deferencia costarricense, 1810-1870", Revista de Historia, 45, pp. 191-228.

Acuña, Víctor Hugo, 2012, "El liberalismo en Centroamérica en tiempos de la independencia", en Javier Fernández Sebastián (coord.), La aurora de la libertad. Los primeros liberalismos en el mundo iberoamericano, Madrid, Marcial Pons.

Acuña, Víctor Hugo, 2014, "La formación del Estado en Nicaragua y Costa Rica en perspectiva comparada: siglos XIX-XX" (manuscrito).

Aldave, Jesús, 2008, La renta del tabaco en Costa Rica (1766-1860), tesis de doctorado inédita, Universidad Pública de Navarra.

Bonilla, Adolfo, 1999, Ideas económicas en la Centroamérica ilustrada, 1793-1838, San Salvador, FLACSO.

Brewer, John, 1989, The Sinews of Power. War, money and the English State 1688-1783, Reino Unido, Cambridge University Press. 
Burkholder, Mark y D. S. Chandler, 1984, De la impotencia a la autoridad, México, Fondo de Cultura Económica.

Corella, Esteban, 2012, "El ejército y la guerra en la formación del Estado costarricense", en Juan Carlos Garavaglia y Juan Pro (eds.), Las fuerzas de guerra en la construcción del Estado: América Latina, siglo XIX, Argentina, Pro Historia.

Corella, Esteban, 2013, "El Ejército en Costa Rica: organización de las fuerzas armadas, sistema de reclutamiento y la construcción del Estado, 1810-1870", tesis de maestría inédita, Universidad de Costa Rica.

Díaz, David, 2001, Comunidad política, identidades, ritos y rituales en la celebración del día de la independencia en Costa Rica, 1824-1921, Informe final del concurso: Culturas e identidades en América Latina y el Caribe, Programa Regional de Becas Consejo Latinoamericano de Ciencias Sociales.

Fallas, Carmen, 2004, Elite, negocios y política en Costa Rica: 1849-1859, Alajuela, Museo Histórico Juan Santamaría.

Fernández, Ricardo, 1928, La independencia y otros episodios, Costa Rica, Trejos y hermanos.

Fernández, Ricardo, 2005, Don Florencio del Castillo en las Cortes de Cádiz, Costa Rica, Editorial de la Universidad Estatal a Distancia.

Garavaglia, Juan Carlos y Juan Pro (eds.), 2012, Las fuerzas de guerra en la construcción del Estado: América Latina, siglo XIX, Argentina, Pro Historia.

García, Jorge Mario, 1971, Orígenes de la democracia constitucional en Centroamérica, San José, EDUCA.

Grandin, Greg, 2000, The Blood of Guatemala: a History of Race and Nation, 1750-1954, Durham, NC, Duke University Press.

Gudmundson, Lowell, 1990, Costa Rica antes del café: sociedad y economía en vísperas del boom exportador, Costa Rica, Editorial Costa Rica.

Huaylupo, Juan Alberto, 2003, La democracia, la burocracia y la autocracia, Costa Rica, Editorial de la Universidad de Costa Rica.

Jiménez, Mario Alberto, 1962, Soberanía externa y relaciones entre el Legislativo y el Ejecutivo en nuestra evolución constitucional, Costa Rica, Editorial Costa Rica.

López-Bejarano, Pilar, 2013, "Organization and Uncertainty: The Administrative Dynamics of the Secretariat of Treasury of New Granada (1806-1851)", en Juan Carlos Garavaglia y Juan Pro (eds.), Latin American Bureaucracy and the State Building Process (17801860), Reino Unido, Cambridge Scholars Publishing.

López-Taverne, Elvira, 2013, "The Structuring of a Bureaucratic Corps in the State Building Process: Chile 1810-1860", en Juan Carlos Garavaglia y Juan Pro (eds.), Latin American Bureaucracy and the State Building Process (1780-1860), Reino Unido, Cambridge Scholars Publishing.

Meléndez, Carlos, 1978, Documentos fundamentales del siglo XIX, Costa Rica, Editorial Costa Rica.

Molina, Iván, 2008, La campaña nacional (1856-1857): historiografía, literatura y memoria, Costa Rica, Editorial de la Universidad de Costa Rica.

Molina, Iván, 2016, La educación en Costa Rica de la época colonial al presente, Costa Rica, EDUPUC. 
Munné, Guillermo, 2006, "Racionalidades del derecho según Max Weber y el problema del formalismo jurídico", Isonomía, 25, pp. 69-100.

Obregón, Clotilde, 1993, El río San Juan en la lucha de las Potencias (1821-1860), Costa Rica, Editorial de la Universidad Estatal a Distancia.

Obregón, Clotilde, 2013, El canónigo Florencia del Castillo, Costa Rica, Editorial de la Universidad Estatal a Distancia.

Palmer, Steven y Molina, Iván, 2012, "Boronas de identidad nacional", Tópicos del humanismo, 113, pp. 1-6.

Pérez, Héctor, "Economía política del café en Costa Rica 1850-1950", en Héctor Pérez y Mario Samper (comps.), Tierra, café y sociedad, San José, FLACSO.

Pinto, Julio César, 1986, Centroamérica de la colonia al Estado nacional (1800-1840), Guatemala, Editorial Universitaria de Guatemala.

Pro, Juan, 2012 "Guerra y Estados en tiempo de construcción nacional: comentarios sobre América Latina en el siglo XIX", en Juan Carlos Garavaglia y Juan Pro (eds.), Las fuerzas de guerra en la construcción del Estado: América Latina, siglo XIX, Argentina, Pro Historia.

Programa Estado de la Nación, 2017, "Proyecto base de datos sobre instituciones públicas en Centroamérica, 1821-1940", Costa Rica, Programa Estado de la Nación/ CONARE.

Reglamento de Hacienda, decretado en 10 de diciembre de 1839, 1839, Costa Rica, Gobierno de Costa Rica, Imprenta del Estado.

Ríos, Evangelina de los, 2013, An Approach to Analyzing a Provincial Administration through the Treasury: Santa Fe, Argentina, in the Later Half of the Nineteenyh Century", en Juan Carlos Garavaglia y Juan Pro (eds.), Latin American Bureaucracy and the State Building Process (1780-1860), Reino Unido, Cambridge Scholars Publishing.

Rodríguez, Mario, 1984, El experimento de Cádiz en Centroamérica, 1808-1826, México, Fondo de Cultura Económica.

Rodríguez, Pablo Augusto, 2013, "La concordia de Costa Rica (1821-1823): revisión de la independencia desde el constitucionalismo", en Aaron Pollack (coord.), La época de las independencias en Centroamérica y Chiapas. Procesos políticos y sociales, México, Instituto Mora.

Rodríguez, Pablo Augusto, 2014, Cambio y continuidad: la Hacienda pública como factor de construcción estatal, Costa Rica 1812-1859, tesis de doctorado inédita, Universidad Pompeu Fabra, Barcelona.

Rodríguez, Pablo Augusto, 2015, "'Aislada y en absoluta orfandad', Costa Rica y la Guerra Civil centroamericana", en Arturo Taracena (ed.), 2015, La primera guerra federal centroamericana, 1826-1829. Nación y estados, republicanismos y violencia, Guatemala, Cara Parens.

Shaw, Carl K. Y., 1992, "Hegel's Theory of Modern Bureacracy", The American Political Science Review, 86, pp. 381-389.

Sibaja, Luis Fernando, 1968, El límite sureste de Costa Rica, tesis de licenciatura inédita, Universidad de Costa Rica.

Silva, Margarita, 1994, Las elecciones y las fiestas cívico-electorales en San José, tesis de maestría inédita, Universidad de Costa Rica. 
Smith, Steven B., 1989, Hegel's Critique of Liberalism: Rights in Context, Chicago, University of Chicago Press.

Taracena, Arturo (ed.), 2015, La primera guerra federal centroamericana, 1826-1829. Nación y estados, republicanismos y violencia, Guatemala, Cara Parens.

Taracena, Arturo, 1996, "Tendencias y perspectivas de la historia política: un comentario", Revista de Historia, número especial, pp. 153-158.

Tilly, Charles, 1992, Coercion, Capital and European States AD 990 - 1992, Reino Unido, Wiley-Blackwell.

Vásquez, Mario, 2004, "El Plan de Iguala y la independencia de Guatemala", en Ana Carolina Ibarra (coord.), La independencia en el sur de México, México, Facultad de Filosofía y Letras-UNAM, pp. 395-430.

Vega, José Luis, 1981, La formación del Estado Nacional en Costa Rica, Costa Rica, Instituto Centroamericano de Administración Pública.

Weber, Max, 1987, Ensayos sobre sociología de la religión I, trad. José Almaraz y Julio Caravana, España, Taurus.

Weber, Max, 2011, ¿Qué es la democracia?, Argentina, Taurus.

Williams, Robert G., 1994, States and Social Evolution. Coffee ans the Rise of National Goverments in Central America, Estados Unidos, The University of North Carolina Press. 